This is a peer-reviewed, accepted author manuscript of the following research article: Man, E., \& Hoskins, C. (Accepted/In press). Towards advanced wound regeneration. European Journal of Pharmaceutical Sciences.

\title{
Towards advanced wound regeneration
}

\author{
Ernest Man and Clare Hoskins*
}

Department of Pure and Applied Chemistry, Faculty of Science, University of Strathclyde, Glasgow, Scotland, G1 1RD

*Corresponding Author:

\author{
Dr Clare Hoskins \\ Pure and Applied Chemistry \\ Technology and Innovation Centre \\ 99 George Street \\ Glasgow \\ G1 1RD \\ clare.hoskins@strath.ac.uk \\ $+441415482796$
}

\begin{abstract}
Wound management is a major contributor towards the economic burden placed upon the national health service (NHS), serving as an important target for the development of advanced therapeutic interventions. The economic expenditure of wound care for the NHS exceeds $£ 5$ billion per annum, thus presenting a significant opportunity for the introduction of alternative treatments in regards to their approach in tackling the ever increasing prevalence of wound management associated problems. As most wounds typically fall under the acute or chronic category, it is therefore necessary to design a therapeutic intervention capable of effectively resolving the pathologies associated with each problem. Such an intervention should be of increased economic viability and therapeutic effectiveness when compared to standardized treatments, thus helping to alleviate the financial burden imposed upon the NHS. The purpose of this review is to critically analyse the various aspects associated with wound management, detailing the fundamental concepts of dermal regeneration, whilst also providing an evaluation of the different materials and methods that can be utilised to achieve maximal wound regeneration. The primary aspects of this review revolve around the three concepts of antibacterial methodology, enhancement of dermal regeneration and the utilisation of a carrier medium to facilitate the regenerative process. Each aspect is explored, conveying its justifications as a target for dermal regeneration, whilst offering various solutions towards the fulfilment of a therapeutic design that is both effective and financially feasible.
\end{abstract}

Keywords: Wound management, materials, antimicrobial, skin, regenerative medicine 
This is a peer-reviewed, accepted author manuscript of the following research article: Man, E., \& Hoskins, C. (Accepted/In press). Towards advanced wound regeneration. European Journal of Pharmaceutical Sciences.

\section{$\underline{1.0 \text { Introduction }}$}

Wound care represents an important aspect of human civilisation, dating back to ancient times where the systematic process of wound washing, plaster creation and bandaging were first described [1]. One of the earliest iterations of wound management utilised honey for antibacterial purposes, grease for the physical separation of the wound from bacteria and lint for wound drainage [1], which from a modern day perspective still covers some of the most important aspects of wound care, i.e. antibacterial activity and the drainage of exudate. In the modern-day, the mitigation and alleviation of such problems are still highly regarded, however unlike the past, the present-day offers significantly more advanced materials which can facilitate wound regeneration at a higher efficacy. Despite the outstanding development in modern-day regenerative strategies, the problems associated with wound care are still vast and challenging, with many issues stemming from socioeconomic circumstances, which have yet to be resolved.

The NHS is an independent public healthcare provider situated within the UK and is the main source of healthcare related treatment and diagnosis for most UK citizens. It is reported that the estimated annual cost of wound care for the NHS is approximately $£ 5.3$ billion, which roughly equates to $4 \%$ of the NHS' total expenditure for the year of 2012-2013 and was also reported to be in excess of $£ 5$ billion for the year of 2015, rivalling the NHS treatment costs that are associated with obesity [2]. It has been reported that within 2012-2013 2.2 million people were wounded, with 278,000 of these cases being venous leg ulcers which resulted in a financial cost of $£ 1.94$ billion, coupled with 87,000 incidences of burn wounds incurring a cost of $£ 89.6$ million [3]. On a per annum basis, an average of $61 \%$ of all total wounds were fully healed which resulted in a financial cost of $£ 2.1$ billion. On the other hand, an average of $39 \%$ of all total wounds did not heal within the year of the study, incurring a cost of $£ 3.2$ billion which is a $135 \%$ more than expensive than the cost associated with healed wounds. Based on this study the per patient cost attributed to fully healed wounds were between $£ 698-£ 3998$, whilst the cost of unhealed wounds between $£ 1719-£ 5976$ [3]. 2.2 million wounded individuals were identified, with $40 \%$ of this population suffering from acute wounds, $48 \%$ suffering from chronic wounds and $12 \%$ suffering from other wounds. Examination of this data indicates that acute and chronic wounds are the most prevalent types, with acute wounds receiving the highest percentage of full recovery and the highest percentage of new development.

Utilisation of the wound cost data coupled with the population of wounded individuals allows for the identification of the financial costs that are attributed to a specific type of wound and whether or not it had healed. Analysis of data suggests that on a per person basis, individuals with acute wounds received the most financial support, especially for those who have not healed from their injury.

Given the relatively low healing statistics and the sizeable population of those suffering from chronic wounds, it can be assumed that the cost per person in the unhealed acute category is higher, so as to prevent the escalation of the acute wound into a chronic state. Despite the fact that the financial support for chronic wounds is the largest amongst the 3 categories; the population size is also the largest, which when examining the financial cost per person, suggests that the financial focus for chronic wounds is towards the maintenance of the affected area so as to prevent further deterioration. Based on these financial figures, it could be suggested that the socioeconomic priority of the NHS is to prevent the transition of acute wounds into chronic wounds, as the financial burden is not only more significant, but can also severely impact the socio-psychological state of the patient, thus causing more complications. 
One of the most significant problems associated with chronic wounds is the drastic reduction in the quality of life, which can occur as a result of continual pain, altered sleeping patterns, altered eating habits, fatigue, stress and reduced mobility. The psychological consequences of these issues include depression and anxiety which can lead to social isolation, thus placing the patient into a positive feedback loop of deteriorating emotional and mental health [4]. Furthermore, the acquisition of a chronic wound can also incur long term socioeconomic problems such as early retirement, early retirement pensions, occupational retraining and financial costs associated with hospital stays, rehabilitation and treatment in countries without universal healthcare.

Evaluation of the financial costs attributed to wound care suggests a substantial opportunity for improvement, especially in regard to the development of a regenerative product that can resolve many of the issues associated with wound management. By focussing development towards an effective regenerative treatment, it will not only reduce the number of hospital admissions but will also reduce the worldwide consumption of antibiotics, thereby hindering the overall progress of antibiotic resistance on a global level. Such a treatment should be designed to heal acute wounds, thus mitigating the deterioration of the wound into a chronic state. The treatment itself should also be as non-invasive as possible, so as to not negatively impact the patient's quality of life, which in turn will prevent the degeneration of patient's psychological and emotional health. To reduce the public's reliance on medically trained professionals, the treatment itself should be user-friendly and of a simplistic nature, thus ensuring ease of application for untrained staff. For the purposes of developing an alternative treatment capable of fulfilling these objectives, this review will therefore explore the skin makeup and the various different aspects that contribute towards an effective regenerative treatment.

\subsection{The human cutaneous system}

The human skin is a dynamic multifunctional organ comprising of different dermal layers which together isolate the pathogenically vulnerable vascular systems from the outside environment. The overall structure of the skin can be classified into three distinct layers, the epidermis, dermis and the subcutaneous tissue. The epidermis is the outermost layer, representing the body's initial line of defence and has variety of different functions ranging from the protection against external microbiota, ultraviolet radiation, chemical and physical stimuli, homeostatic thermoregulation, trans-epidermal moisture retention and physical sensory perception. The epidermis is $0.05-1 \mathrm{~mm}$ thick and is sectionalized into four to five distinct sub-layers with respect to the area of skin being studied. These sub-layers are the stratum corneum, stratum lucidum, stratum granulosum, stratum spinosum and the stratum basale, Figure 1 . The composition of each sub-layer is primarily made up of keratinocytes that are phenotypically unique in respect to the specific function of the sub-layer and is also composed of melanocytes and Langerhans cells. The physiology of the skin has been outlined extensively elsewhere and so will not be addressed within this review.

\subsection{Skin microbiome}

The skin microbiome exists in equilibrium with the mammalian body, whereby the cutaneous flora serves to refine and educate the immune system, resulting in an appropriate immune response that can regulate the development of the epidermal microbiota. There are a variety of factors associated with the development of microbiota which determine the strain and concentration of pathogenic growth. These factors include the temperature, humidity, density of sebaceous glands, physiological age and sebum production. Areas of increased humidity and temperature such as the auxiliary vault and groin promote the growth of certain gram negative 
bacteria, S.aureus and coryneforms. Areas with a high density of sebaceous glands, such as the face tend result in the growth of lipophilic microbiota which include Malassezia spp and Propionibacterium spp. On the contrary areas of with consistent temperature fluctuations and low humidity, such as the arms and legs, result in a microbiome concentration that is significantly less than their warm and humid counterparts. In regard to the factors of age and sebum production, different physiological responses are associated with different phases of biological age. An example of this is puberty which result in increased sebum production, further encouraging the proliferation of specific lipophilic bacteria which causes a significant disparity in bacterial diversity. Despite the fact that sebum acts as an antibacterial layer, certain strains such as P.acnes can hydrolyse the triglycerides found in sebum, leading to its successful migration into the sebaceous gland. This subsequent imbalance results in the increased proliferation of commensal bacteria such as P.acnes, causing a build-up of secretions such as proteases, hyaluronidases and lipases which breakdown the tissue lining of sebaceous glands and hair follicles [5]. This then follows a positive feedback cycle whereby the breakdown of tissue lining causes increased pathogenic exposure, leading to increased migration of P.acnes in the pilosebaceous units, thus exacerbating the severity of the injury. Commensal microbiota is typically harmless when existing on a healthy sebaceous surface, however they become pathogenic when the surface barrier becomes impaired, resulting in the occurrence of infections at the site of trauma. Although commensal bacteria are not usually responsible for the incurrence of the wound itself, their presence within the site of injury can lead to chronic inflammation, thus preventing the skin from undergoing a full recovery [6].

Most skin bacteria can be categorised into the different phyla of Proteobacteria, Bacteriodetes, Firmicutes and Actinobacteria, however the balance in which these bacteria exist is purely dependent on the area of the body being examined. Actinobacteria contribute towards the greatest population size for epidermal skin, whilst Bacteriodetes and Firmicutes are most abundant in the gastrointestinal area. Desiccated areas of skin typically have the greatest variety of microflora, with a highly diversified representation of all four bacterial phyla. On the other hand, areas of high humidity result in decreased diversity with Corynebacterium spp and Staphyloccus being the most dominant organisms.

\subsubsection{Bacterial modulation}

The growth and development of bacterial flora is modulated by host-microbial homeostasis which maintains the equilibrium between the immune system and the microbial ecosystem that exists on the epithelial layer. This is continually regulated by keratinocytes via pattern recognition receptors which discriminate via pathogen associated molecular patterns which include the lipoteichoic acid that is present in gram positive bacteria, lipopolysaccharides that are found in gram negative bacteria, nucleic acids and flagellin. The activation of the pattern recognition receptors initiates the secretion chemokines, cytokines and antimicrobial peptides, which eradicates targeted microorganisms including bacteria, enveloped viruses and fungi [7]. Whilst unwanted bacterial strains can trigger the cascade leading to the secretion of antimicrobial peptides, commensal bacteria such as P.acnes S.epidermidis are largely ignored due to their immunologically harmless nature when existing on healthy epidermis and may positively benefit the host in a synergistic manner. Taking S.epidermidis as an example, its commensal nature may have developed as a co-evolutionary by-product with its human host, resulting in favourable traits that help to extend the mortality of the human host. Such traits include low cytotoxicity as well as the production of bacteriocins which are antagonist molecules that supress the development of more pathogenic strains within the same species. In the case of S.epidermidis, the bacteriocin produced include epidermin, epicidin 280, epilancin k7 and Pep5 which are lantibiotics capable of inhibiting the development of methicillin 
This is a peer-reviewed, accepted author manuscript of the following research article: Man, E., \& Hoskins, C. (Accepted/In press). Towards advanced wound regeneration. European Journal of Pharmaceutical Sciences.

resistant S.aureus (MRSA) and other types of s.epidermidis [8]. Another synergistic benefit includes the secretion of lipoteichoic acids which suppresses skin inflammation during wound regeneration, thus suggesting that such commensal bacteria are important for the maintenance of homeodynamic skin inflammation. Although its commensal nature has been of benefit to its human host, s.epidermidis is still considered to be an opportunistic pathogen in scenarios where the medical devices are integrated into immunocompromised patients and when the epidermis is breached, leading to its migration of the bacteria into the blood stream.

\subsection{Permeability: Healthy vs compromised skin}

Healthy skin pertains to the retention of a fully functional epidermal layer, whilst compromised skin is associated with the impairment of the epidermis resulting in the exposure of the underlying dermis. In regard to the constitution of each layer, the epidermis is innately hydrophobic due to its lipid-based constituency, whilst the dermis is hydrophilic due to its high osmotic saturation relative to the other dermal layers. Taking these facts into consideration, healthy skin is initially hydrophobic, but upon its impairment, extrudes a hydrophilic nature. Alterations in the skin's hydrophobicity need to accounted for when developing an appropriate treatment for the regeneration of the dermis and epidermis, as the regenerative agent will need to be fine-tuned to ensure maximal absorbency within the targeted area.

As the hydrophobic nature of the epidermis results from the accumulation of lipids, transdermal drugs need to include a lipophilic component to be able to dissociate and bypass the epidermal barrier. The main issue regarding trans-epidermal drug delivery is the fact that the lipid pathway occurs between tightly packed keratinocytes, leading to severe restrictions in drug permeation rates which are further affected by the size and innate polarity of the drug molecule. It is proposed that the primary route taken by transdermal transport occur through the structural defects found within the lipid matrix, existing as a nano-pinholes, dislocations and grain boundaries [9]. It was postulated by S.Mitragotri that excessive water conditions can increase the formation rate of the defects, leading to enhanced permeation. This is based on the fact that the swelling of the SC, SC bilayer fluidization, coupled with the packing imperfection of the SC bilayer components will increase the formational likelihood of structural defects [10]. The permeability of hydrophobic solutes through the epidermal layer display a strong bias towards size selectivity, whereby solutes with a radius of less than 4 Angstroms have significantly higher rates of diffusivity. This is mainly attributed to the radial size of the molecular cavities within the epidermal layer, thus indicating that the hydrophobic molecules with a radius smaller than the molecular cavity will experience less steric hindrance, leading to increased permeability. In regards to the permeation of hydrophilic molecules, it is hypothesized that the diffusion pathway occurs through the pores within the SC and are affected by the factors of porosity, pore size and tortuosity. Generally speaking, hydrophilic molecules with a reduced hydrodynamic radius show higher rates of skin permeability, leading to a trend line which displays increased exponential decay in skin permeability relative to the increase in hydrodynamic radius. Quantitative analysis confirms that the permeation of hydrophobic solutes through a healthy epidermis is significantly higher than that of hydrophilic solutes. When comparing the relative permeability of hydrophilic and hydrophobic molecules based on similar molecular weights, the permeability of the hydrophobic molecules is typically a couple of magnitudes higher than their hydrophilic counterparts.

Dysfunction of the epidermis leads to the increased permeability of both hydrophilic and hydrophobic molecules, whereby the increase in hydrophilic solute permeability is significantly higher than their hydrophobic counterparts. A study conducted by Schlupp et al tested the permeability of solutes with differing hydrophilicities, caffeine, sorbic acid and 
testosterone, on skin samples of various conditions. The results indicated that the transepidermal water loss (TEWL) was approximately three times higher in abraded skin than untreated skin for all three solutes, the lag time was significantly reduced for caffeine which is the most hydrophilic substance of the three, whilst testosterone, the most hydrophilic solute, received minor reductions in lag time. The total percentage recovery for all three solutes were similar, showing a minor decrease in total recovery when comparing abraded skin to untreated skin. The test parameter of total percentage drug uptake indicated an approximate increase of $700 \%$ for caffeine when comparing abraded skin against untreated skin, whilst testosterone uptake increased by less than $200 \%$ [11]. The general consensus indicates that the impairment of the epidermal barrier will lead to an increased uptake of both hydrophilic and hydrophobic molecules, however the main disparity in their permeability is the relative difference in the rate of uptake, whereby the most hydrophilic molecule, caffeine, displayed the most significant increase in drug uptake. Based on these results, it can be concluded that the increased exposure of the dermis leads to the increased absorption of hydrophilic molecules. Due to the fact that the composition of the dermis is approximately $70 \%$ water, compared to the SC which is approximately $15 \%$, it is understandable that dermis has an increased affinity for hydrophilic components, leading their increased uptake upon the impairment of the epidermis.

\section{Injury - sources of cutaneous impairment}

Dysfunction of the epidermal barrier can be attributed to a variety of different sources ranging from direct physical trauma, disruptions to regular physiological function and chemical, thermal, electrical trauma, etc. The relative ability for the body to recover from subcutaneous impairment is highly dependent on the source of the injury and the intensity of the injury. Direct physical trauma can be classified into various categories including lacerations, punctures, abrasion, shearing injuries and blunt trauma. Burns can be classified into chemical, radiation, thermal and electrical, which in themselves are classified into varying degrees of severity. The severity of barrier impairment correlates to the increase in the risk of infection, which in itself can lead to reductions in the quality of life and the possible chance of bacteria-induced mortality. Various consequences can occur as a result of injury, ranging from cutaneous scarring, psychological trauma, changes in lifestyle and amputation in more severe cases. The immediate effect of skin impairment is the risk of bacterial infection as the permeation of bacterial bodies will lead the colonization of the wound area and its subsequent proliferation leading to the further degeneration of the wound site. Presence of the bacterial colony will not only inhibit the regeneration of the wound but may exacerbate the injury depending on the type of secretory molecule that is released. Upon the further penetration of deeper subcutaneous layers, the bacteria may infect the areas surrounding major vascular networks leading to sepsis when if the colony infects the blood stream. Based on this fact, it is imperative to determine an effective antibacterial method that can successfully eliminate bacteria before their migration into the deeper subcutaneous layers.

\subsection{Physical traumas}

Physical trauma implies the causative wounding by a physical object with applied directional forces, leading to tissue damage as the object contacts the body. Physical traumas include: blunt force, sheer force, abrasive force, lacerations or punctures. The general factors determining the extent of injury include the morphology of the object in question, the sterility of the object, its frictional coefficient, the extent of the directional force applied, the relative resistance of the bodily area to which the trauma is applied, as well as its physical composition. The morphology of the object in question determines the nature of the trauma, either being penetrative, blunt or abrasive. The sterility of the object determines the consequences and further complications 
associated with physical traumas that bypass the epidermal barrier. The frictional coefficient determines the relative abrasive force, as well as the penetrative potential of the object when coupled with its morphology. The relative resistance of the bodily area and its associated physical composition, determine the combined ability of the tissue groups to resist injury, thus establishing the minimal force needed to wound with regards to the type of physical trauma applied. Physical traumas can be characterised into various categories, blunt trauma [12] which causes internal haemorrhaging, shear injuries [13] which also causes internal haemorrhaging and penetrative trauma which typically results in an open wound, i.e. abrasion, lacerations and punctures.

\subsection{Burn traumas}

Burn injuries are classified by their severity level, whereby first-degree burns are the most minor and third-degree burns being the most major. Burn injuries vary depending on the source, with thermal burns originating from localised heat sources, cold burns originating from localised cold sources, radiation burns originating from radiation sources, chemical burns originating from strong acids, bases, solvents etc. and electrical burns which originate from the close contact with a strong electrical source. The effects of burn traumas vary greatly, however the general consensus follows the increase in, vasodilation and capillary permeability, leading to the continual leakage of plasma into the surrounding interstitial space for approximately 48 hours. Deeper burns generally result in higher losses of red blood cells as a result of acute vessel thrombosis. Red blood cells also haemolyse as a result of extreme heat, reducing its lifespan, which may lead to onset of anaemia. Unlike the heavy contamination involved in penetrative trauma, the immediate contact between the source of the burn and the skin result in instant sterilisation of the cutaneous contact area. Burn related infections typically occur within the week following the injury, leading to occurrence of sepsis which then further triggers inflammatory responses resulting in tissue damage and organ failure. In the case of non-severe burn traumas, blisters can form as a defence mechanism for preventing the escalation of further injuries. Fluids such as lymph fluid, plasma and blood can gather in between the epidermis and dermis creating a fluid filled pocket of various sizes. This pocket acts as a cushion to prevent any further damage, thus protecting the subcutaneous tissue lying beneath the epidermis. In regard to the classification of burn traumas, the severity of injury is dependent on the depth of engagement between the cutaneous tissue and the source of insult. First degree involves the epithelium becoming erythematic without the formation of blisters. Second degree burns are sub divided into second degree superficial which follows the engagement of the papillary dermis leading to blister formation, whilst second degree deep involves the reticular dermis resulting in the initial occurrence of eschar formations. Third degree is the most severe with eschar formations being predominant throughout the wound [14]. An eschar is a piece of protective necrotised tissue that provides temporary cover for the wound and will naturally slough or dissolve away within less than a month. Eschar have a leather like texture resulting in the complete loss elasticity, which can negatively affect the vascular flow of surrounding vessel systems [15]. As the eschar is piece of necrotic tissue, it acts as a suitable culture medium for bacterial proliferation leading the development of microbiomes deep within the eschar, resulting in pathogenic colonization of deeper tissues. To counteract this issue, the choice of topical formulation requires an antimicrobial agent capable of penetrating the eschar, however due to its low permeability, extensive quantities of topical products are required, thereby resulting in a need for a product that is effective, with minimal toxicity.

\subsection{Biological injury}

Dermal injuries can be induced by the activities of biological components produced from pathogens. In the case of bacteria induced dermal damage, different enzymes are produced 
which can enzymatically degrade the dermal barrier. One of these enzymes are bacterial proteases which facilitate dermal injury through two distinct mechanisms. The first mechanism is direct damage to the structural integrity of the skin barrier via the enzymatic cleavage of structural proteins that make up the ECM. An example of this is the epidermolytic toxin (ET) produced from $S$. aureus which identifies and selectively cleaves the desmosomal caherin attributed to cellular adhesion, desmoglein 1 [16]. Another protease secreted by $S$. aureus is staphopain A (ScpA) and staphopain B (ScpB) which are both attributed to the enzymatic lysis of elastin which is one the primary proteins attributed the structural integrity and elastic potential of the ECM [17].

The other mechanism is indirect damage via the continual stimulation of the inflammatory cascade which impairs the healing process. This occurs as a result of the bacterial protease interfering with the natural defence mechanisms of the body. A variety of different mechanisms can be disrupted ranging from the activities of professional phagocytes, the chemokine and cytokine network, complement cascade and cell signalling etc. By disrupting these processes, the bacterial population becomes unaffected by these specific defence mechanisms, thereby allowing further bacterial propagation to occur. Overall the combination of both direct and indirect mechanisms result in increased dermal damage, which not only intensifies the speed of deeper dermal penetration, but also increases the susceptibility of the body to deep tissue infections, thus leading to higher chances of sepsis occurring.

\section{Topical antibacterial interventions}

The pathogenic colonization of impaired cutaneous tissue is one of the most common processes that lead to the further escalation of pathologies associated with wound infection. Such infections can escalate leading to the development of further complications such as septic wounds, which can affect the mortality of the victim and peripheral neuropathy stemming from the infection of the nervous system. To prevent the development of such complications, various topical antibacterial methods have been developed and explored, such as topical antibiotics, topical biocides and nano-metals which together display a wide range of antibacterial effects.

\subsection{Antibiotics}

Antibiotics are a common method used to combat bacterial infections, either by the use of bactericidal or bacteriostatic effect. Commonly used antibiotics for wound healing include mupirocin, fusidic acid, neomycin, bacitracin, polymyxin B and retapamulin. The general consensus regarding the benefits of antibiotics is the fact that they can used as a preventative measure pre-infection and can also be used post-infection. They are generally fast acting and can be used to eliminate a vast range of bacterial strains. Although the effectiveness of each antibiotic is dependent on the bacterial strain that it is applied to, the primary issue lies with the development of bacterial resistance which develops as a result of increased antibiotic use leading to further reductions in antibiotic efficacy. Other major problems associated with antibiotic use, reported by Yang et al. is the weakening of the immune system and the reduction of antibiotic efficacy as a result of the remodelling of the metabolite environment [18]. Some other side effects associated with antibiotic use include, the patients' innate bio-incompatibility with specific antibiotics which may lead to unwanted immune reactions, or fungal infections as result of the elimination of beneficial bacteria causing pathogenic homogeneity of specific fungal species and its interactions with certain medications. In regards to the topical application of antibiotics, the collective efficacy of all commonly used topical antibiotics covers the main spectrum of cutaneous microbiota. Based on the overall outlook of antibiotic use, it is clear that 
This is a peer-reviewed, accepted author manuscript of the following research article: Man, E., \& Hoskins, C. (Accepted/In press). Towards advanced wound regeneration. European Journal of Pharmaceutical Sciences.

this is not a sustainable long-term method as the global consumption of antibiotic is increasing which leads to worldwide problem of gradual antibiotic resistance [19].

\subsection{Topical biocides}

Topical biocides represent an alternative method for cleansing of topical microbiota. Antibiotics and biocides both function via the inhibitive targeting of key cellular processes leading to bacterial death, however certain mutated strains may survive resulting in successful reproduction and therefore the subsequent transfer of mutational resistance. Unlike antibiotics, biocides are not strictly regulated, leading to concerns over possible developments in biocide resistance. In essence the main difference between antibiotics and biocides is in the regulatory framework that governs its distribution, coupled with the fact that antibiotics are typically derived from natural sources, whilst biocides are derived from synthetic sources. The applications of topical biocides generally follow a wider spectrum of use, ranging from personal hygiene products to surface disinfectants, whilst antibiotics are primarily for restricted medical use only. Topical biosides commonly used include chlorhexidine, triclosan, povidoneiodine, alcohol and hydrogen peroxide.

\subsection{Bacteriophage therapy}

Bacteriophages are a type of specialised virus which parasitizes bacteria via the injection of viral nucleic acids. The mechanism of bacteriophages follows two distinct pathways which both stem from the initial injection of the viral chromosome, as shown in Figure 3. One of these pathways is passive in nature, involving the incorporation of viral chromosomes into the genome of the host bacteria, where it lays dormant. From this point the integrated viral chromosome either replicates in parallel with the host or detaches from the host genome which may then lead to the next bacteriophagic pathway. This pathway follows the multiplicative replication of the viral chromosomes resulting in a build-up of more newly formed bacteriophages within the bacteria. Once the number of viral copies exceeds the maximal capacity of the bacterial cell, lysis of the host cell wall then occurs, releasing all of the newly formed bacteriophages, leading to the repeat of the bacteriophagic cycle. Benefits with regards the use of bacteriophages include its specificity of parasitism, targeting only bacteria whilst ignoring animal and human cells. The specificity of bacteriophages is also more particular than antibiotics, targeting bacterial flora that fall within set parameters which result in the termination of specific pathogens, leaving commensal bacteria to freely replicate. As bacteriophages are highly specific, mixtures of bacteriophage cocktails are typically applied to ensure the complete elimination of all targeted bacteria and their associated subspecies.

\subsection{Monoclonal antibody therapy}

Monoclonal antibodies (mAbs) are specifically engineered antibodies for immunotherapy that are purely homogenous in regards to their diversity. Antibacterial mAbs are developed with the intention of either killing the bacteria or halting its pathological processes, whereby the mechanism of action is determined by a variety of different parameters including the characteristics of the target, its associated pathology and the structure of the mAbs. One of these methods for the negation of bacterial pathology follows the neutralisation of exotoxins produced from bacterial activity, whereby the mAbs bind to the exotoxin thus forming a complex, which then gets removed by the reticuloendothelial system. Other methods include opsonophagocytosis which is the induction of phagocytic engagement by mAbs, direct lysis of the bacterial body via the binding of mAbs, etc [20]. Commonly used monoclonal antibodies used for wound management are raxibacumab, obiltoxaximab and bezlotoxumab. 
Issues arising from the use of antimicrobial $\mathrm{mAb}$ therapy include the obstacles associated with the selection of pathogenic targets as the primary objective typically involves the mAbs binding onto the exotoxins or to the bacterial surface antigens. This binding problems involves the outer membrane proteins (OMPs), where these OMPs are masked by exopolysaccharides thus preventing antibody binding [49]. Other issues include the problem of bacterial resistance against $\mathrm{mAbs}$, which despite its distinctive antimicrobial mechanisms, is still affected by the bacterial defensive mechanisms developed after extensive periods of evolution. Such defensive mechanisms include the production of proteins that neutralise antibodies via binding and the secretion of degradative proteinases that degenerates the mAbs, leading to its loss of function [20].

\subsection{Nano-metal therapy}

Nano-metals and nano-metal oxides offer great flexibility in regards to their modifiability, which allows them to be attuned for specific antibacterial activities. The flexible nature of nano-metals and nano-metal oxides are represented by their antibacterial efficacy which is associated with the changes in morphological size, shape and roughness, as well as the zeta potential, functionalization and its synergy when combined with other nano-metals. Based on the different variations of these parameters, the efficiency of the antibacterial mechanism can be altered, allowing the nano-metal to be tailored to a specific situation such as its usage against bacterial films. The current antimicrobial nano-metal and nano-metal oxides used for wound management are silver [21], gold [22], copper [23], aluminum oxide [24], calcium oxide [25], cerium oxide [26], copper oxide [27], magnesium oxide [28], silver oxide [29], titanium dioxide [30], yttrium oxide [31] and zinc oxide [32].

\subsubsection{Mechanism of action of nano-metals}

The primary mechanism associated with the antibacterial properties of nano-metals is the release of reactive oxygen species (ROS), in which hydrogen peroxide, hydroxyl radicals, singlet oxygen and superoxide anions are the most prominent naturally occurring species. The oxidation reaction of these oxidative species with specific cellular matter, such as proteins, nucleic acids and lipid membranes can accumulatively degrade the vital physiological functions of the bacterial cell, as shown in Figure 4, thus leading to cell death [50]. The oxidative stress resulting from the accumulation of ROS affects a variety of different structures including the genotoxic degradation of DNA, mRNA, ribosomes, inhibition of signalling via the dephosphorylation of the phosphotyrosine residues and the dysfunction associated with the degradation of membrane proteins, including ion channels and receptors which leads to bacterial membrane damage and therefore increased permeability [29]. The general consensus regarding the effects of ROS is that the higher the concentration of ROS, the higher the severity of cellular damage to the internal and external architectures of the bacterial body, which in turn affects the biochemical cascades, leading to overall loss of function.

Electrostatic interactions induced by the metal cationic core can also inhibit bacterial activity via the disruption of the cellular membrane. Electrostatic attraction occurs between the metal cation and the negative charge on the bacterial surface, which is due primarily to the presence of carboxylic groups. This results in the increased adsorption and bonding of metal cations onto the cell membrane surface, disrupting the organisation of the cell wall which lead to changes in the permeability and structural integrity of the bacterial cell membrane. Eventually, the accumulation of cations increases the membrane permeability to the point in which the structural integrity of the membrane is below the threshold needed for the bacteria to retain its cellular contents, thus resulting in gradual loss of key cellular substances that are needed to maintain the vitality of the bacterial cell. 
Disruptions to proteins and enzyme cascades are not only affected by ROS but are also affected by the catalytic increase in protein-bound carbonyls resulting from the interactions between amino acids and the metal cations. These interactions primarily revolve around the metal coordination bonds that occur via the reaction of the metal cation with the thiols, disulphide bridges and other sulphur functions that exist within the protein's secondary, tertiary and quaternary structures [33]. The formation of reversible sulphur-metal complexes lead to temporary structural changes in the overall folding pattern of the protein, preventing the conformational binding of substrates, thus leading to the deactivation of the enzyme and its accompanying biochemical cascades.

\subsubsection{Factors affecting the antibacterial activity of nano-metal and nano-metal oxides}

The morphological parameters of nano-metals and nano-metal oxides are an important factor which influence its interactions with bacterial bodies, as well as its release of ROS. The effects of size on antibacterial efficacy generally indicate that smaller nanoparticles (NPs) have an increased probability of contacting and bypassing through the bacterial membrane, due to increased surface area to volume ratio [53]. Changes in NP size can also affect the output of metal ions, which depending on the type nano-metal can be cytotoxic, i.e. the smaller the size of $\mathrm{CuO}$ the larger the increase in copper cations, resulting in higher levels of toxicity [34].

The physical shape of the nano-metal is an important factor, affecting its ability to interact with the bacterial membrane, as well as the generation of ROS. A variety of shapes can be formed, including nanocubes [35-37], nanospheres [37,38], flat nanosheets [39], nanorods [40-42], nanoclusters [43-45] and nanoprisms [46] which all produce different levels of antibacterial effect. Alshareef et al, tested the antibacterial efficacy of copper nanospheres and nanocubes against the gram-negative strain Escherichia coli and the gram-positive strain Enterococcus sp. Tests demonstrated that both copper nanospheres and nanocubes were effective against both gram positive and negative strains, however the nanocube morphology had the greatest antimicrobial effect, which suggests that the cubic profile resulted in higher levels of reactivity against the bacterial strains [37]. Zhang et al created a composite nanosheet comprising of polydopamine-graphene nanosheet-nanosilver, for antibacterial testing against gram-negative Escherichia coli and gram-positive B. subtilis. Results from the experiment indicated the positive inhibition of bacterial growth for both gram-negative and gram-positive strains, thus confirming the synergistic effects of graphene nanosheets and nano-silver against bacteria [39]. A study conducted by Mahmoud et al, investigated the antibacterial effects of gold nanorods (GNRs) on the gram-positive strains Propionibacterium acnes and Staphylococcus aureus. The GNRs were bound to different polymers to form the complexes polyacrylic acid-GNR, polyethylene glycol-GNR and polyethylene glycol-cystamine-GNR, which were then mixed with bacterial growth media to determine the minimum inhibitory concentration (MIC) and minimum bactericidal concentration (MBC). The results indicated that GNRs showed promise for the inhibition of the bacterial strains, however further research is needed [40]. Sibidou et al conducted research on the effects conjugated gold nanoclusters for antibacterial purposes. This method utilizes gold nanoclusters which can be easily conjugated with numerous molecules, allowing the successful transport of antimicrobial substrates into the bacterial body, thus increasing the overall bactericidal effect. Different complexes were made using 6mercaptohexanoic acid (MHA) as the conjugate substrate resulting in MHA-Au nanoclusters (NC), MHA-AuNP and MHA-Au(I) which were then tested against S.aureus to determine their antibacterial efficiency [43]. Based on the results of the experiments, it was deduced that MHAAuNCs were the most effective form of nanogold, with the highest bactericidal efficiency of approximately 95\%, whilst MHA-AuNP was approximately 3\% efficient and MHA-Au(I) approximately $5 \%$ efficient. 
Nanoparticle roughness is a physical parameter that is generally lacking in terms of research, however experiments conducted by Rizello et al. deduced a substantial response of E. coli upon contact with nanostructured gold with an approximate roughness of $100 \mathrm{~nm}$ [47]. Results indicated the occurrence of topographically specific physiological responses by $E$. coli, whereby the surface topography of the nanogold triggered the upregulation of genes associated stress, when compared to a flat surface. Particle roughness is not only capable of inducing a physiological response in bacteria but can also cause direct physical damage to the membrane. This occurs via the shear force generated by the movement of the bacterial body whilst adhered to the nanoparticle, leading to the occurrence of a physical tear in the bacterial membrane [48]. In general, the surface roughness determines the level of bacterial adhesion that occurs, where the increase in roughness correlates to an increase in surface area, thereby promoting the increased adsorption of bacterial proteins which leads to an overall decrease in the levels of bacterial adhesion [49].

The zeta potential is a measure of the electro-kinetic potential that exists between the boundaries of the physical and liquid state. The zeta potential of a nanoparticle is a key factor which influences the electrostatic attraction between the metal cation and the negative charge that exists on the bacterial membrane surface. In general, the zeta potential of the bacterial surface is in the negative $\mathrm{mV}$ range, with gram-positive bacteria having a slightly higher average $\mathrm{mV}$ value than their gram-negative counterparts [50]. Due to the difference in zeta potentials between the bacterial surface and the cation, electrostatic attraction occurs leading to the penetration of cations, resulting in the subsequent production of reactive oxygen species (ROS) as well as protein degradation via direct contact with the cation. The zeta potential of the nanoparticle also determines the stability of the colloidal suspension, whereby a more extreme zeta potential value results in higher levels of colloidal stability. The general consensus regarding the colloidal stability of nanoparticles follow the fact zeta potential values above +30 $\mathrm{mV}$ and below $-30 \mathrm{mV}$ provide increased stability, whereas values within the $+25 \mathrm{mV}$ to -25 $\mathrm{mV}$ range will start to cluster over time [51]. Variable nanocomposites made using different nanometals can provide synergistic effects surpassing the efficacy of homogenous nanometals, such as the zinc oxide-silver ( $\mathrm{ZnO}-\mathrm{Ag}$ ) nanocomposite which has higher antibacterial efficacy than $\mathrm{ZnO}$ NPs as a result of the increased interactions between the nanocomposite with both gram-positive and gram-negative bacteria [52]. External conditions have also been documented to affect the antimicrobial properties of various nanometals and nano-metal oxides. In general, the increase in temperature stimulates the production of ROS by increasing the thermo-kinetic activity between the electrons and oxygen, resulting in increased interaction which in turn increases the antimicrobial efficacy of the NPs. $\mathrm{pH}$ is also an important external factor, which in the case of $\mathrm{ZnO}$ NPs result in increased antimicrobial activity when the $\mathrm{pH}$ range is approximately between $\mathrm{pH} 3.5-5.8$, leading to increased adhesion of the NPs to the bacterial surface [53].

\subsubsection{Nano-metal skin permeability}

For the specific purposes of cutaneous wound regeneration, antimicrobial nano-metals should be applied in a topical manner, therefore investigation is required into the factors affecting the cutaneous permeability of nano-metals. It is important that such factors are to be investigated as highly permeable nano-metals can bypass specific cutaneous layers, leading to the systemic circulation and accumulation in specific organs which may lead to detrimental toxicity. As the characteristics of nano-metals vary greatly from one another, it cannot be assumed that different nano-metals with identical particle sizes will produce similar cutaneous permeability results. As a comparison, Gontier et al. demonstrated that titanium dioxide $\left(\mathrm{TiO}_{2}\right)$ nanoparticles 
between 20-200 nm could not penetrate through the SC of human skin [54], whilst Larese et al. demonstrated that silver NPs of $25 \mathrm{~nm}$ size were capable of penetrating the upper limits of the human epidermis [55]. For some nano-metals such a nanogold, the relationship between particle size and permeability indicate that the permeability coefficient increases as a function of decreasing particle size, which in turn results in greater cutaneous penetration [56]. Based on the evaluative data procured by Larese et al. the general consensus indicates that nanometals below $4 \mathrm{~nm}$ can penetrate through healthy epidermis, 4-20 $\mathrm{nm}$ can penetrate through damaged epidermis and possibly through health epidermis, 21-45 $\mathrm{nm}$ can only penetrate through damaged skin, whilst $>45 \mathrm{~nm}$ cannot penetrate through skin [57]. The shape of the nanometal also plays a role in the permeability of the nano-metal, which in the case of nanosilver follows the triangular, rod-shaped and spherical morphologies. Based on experiments conducted by Tak et al. the in vivo mouse skin penetration results indicated that rod shaped nanosilver had the highest degree of permeability, leading to a blood-silver plasma concentration value that is double that of the value observed with spherical nanosilver and also the silver nanorod density was approximately eight times higher than that of the spherical nanosilver. On the contrary, triangular shaped silver nanoparticles possessed the lowest blood concentration and the lowest density values when compared against both the rod shaped and spherical shaped particulates [58].

\section{Enhancement of natural regeneration}

Four standard processes are associated with the natural regenerative pathway of human cutaneous tissue. These four processes occur in the order of haemostasis, inflammation, proliferation and maturation, where each of these processes overlap with the preceding processes. Haemostasis follows the six chronological mechanisms of platelet plug formation, adhesion of platelets, activation of the platelets, aggregation of the platelets, activation of intrinsic and extrinsic coagulation cascades, as well as clot resolution. The initial formation of the platelet plug begins after immediate vasoconstriction, which leads to the agglomeration of platelets on the sub-endothelium surface, resulting in the formation of a fibrin mesh. Blood then begins to increase in viscosity as a result of procoagulants which result in clot formation, trapping more platelets and blood cells in the process, thus preventing further blood loss. The next stage is inflammation which involves the mass localisation of leukocytes and transudate which helps to regulate bleeding and prevent further infection. The gathering of transudate at the site of injury supplies the necessary components to promote cellular repair, whilst the leukocytes remove foreign debris, pathogens, as well as damaged cells. After the inflammation stage is the proliferation stage which follows the resynthesis of cutaneous tissue, restoration of vasculature and the closure of the site of lesion. The resynthesis of tissue in the case of the epidermis involves the activation of the pericytes found in the SB which can differentiate into the necessary cell types. Granular tissue then begins to form via the increase in the proliferation of fibroblasts which leads to the increase in interferon-beta and chemostatic factors. This then stimulates cellular migration, as well as the synthesis of collagen and elastin, resulting in gradual repair of the ECM [59]. The restoration of vasculature follows the angiogenic mechanisms of both cell division and germination to produce collateral veins which then get remodelled into the necessary blood vessel [60]. The closure of the lesion revolves around the mechanism of contraction produced by myofibroblasts which are attached to the periphery of the lesion, thus gradually reducing the size of the wound. The final stage is maturation which involves the mass remodelling of the ECM at the site of injury. Various processes occur including degradation, reorganisation and synthesis to achieve maximal tensile strength coupled with the restoration of normal tissue function where possible. In this stage, collagen- 
III is converted into collagen-I and any cells that are no longer required are removed by apoptosis. The collagen that is applied in the proliferation stage is unaligned, resulting in scar tissue with low elasticity, however water is reabsorbed into the scar allowing the collagen to realign in parallel before the cross-linking process occurs. This realignment and cross-linking reduces the thickness of the scar and increases the tensile strength of the scar; however, the overall tensile strength of damaged skin is still weaker than that of healthy unimpaired skin.

The four stages that are involved in cutaneous regeneration are complex in nature and can be considered as fragile weak points, given that any disruptions to these processes can result in chronic wounds and thus the prevention of complete regeneration. However, the processes that constitute to the four stages of wound recovery can also be targeted for regenerative purposes by improving the rate of recovery via the introduction of different factors and compounds, thus allowing a certain degree of control over the final state of the scar tissue.

\subsection{Compounds promoting cutaneous regeneration}

The induction of pathological damage to cutaneous tissue activates the four stages of natural regeneration, which can be targeted to promote greater efficacy in cutaneous healing. Within the process of cutaneous regeneration, growth factors are secreted to promote specific effects in accordance to the stage of cutaneous healing, i.e. the release of granulocyte macrophage colony stimulating factor (GM-CSF) in the inflammatory phase to promote improved inflammatory effects, or transforming growth factor beta (TGF- $\beta$ ) in the proliferative phase to enhance the migratory and proliferative capacity of keratinocytes, Table 1 . It should be noted that there is not one specific growth factor that is associated with a particular regenerative phase, as the effects of a singular growth factor is limited, but instead relies on a combination of specific growth factors that work in tandem to achieve the desired physiological effect. The application of different combinations of growth factors can be synergistic in nature, thus improving the overall efficiency of natural cutaneous regeneration. This can also serve as a way of modulating the expressions of specific growth factors, such as in the case of connective tissue growth factor (CTGF) and TGF- $\beta$, where TGF- $\beta$ mediates the downstream expression of CTGF [61]. The benefits of cutaneous application allow for the localised absorption of the growth factor or regenerative compound at the site of injury, whilst avoiding the possible disadvantages and negative impacts associated with systemic absorption. The disadvantages of systemic absorption not only involve the reduction in the possible efficacy of the compound via the decrease in concentration below the therapeutic threshold, but can also lead to the build-up of the compounds in unwanted locations, i.e. in the liver, stomach and brain, where it may cause organ degeneration. Based on this, it is also important to ensure that the topical application of the compound strictly results in topical absorption only and does not encroach upon systemic absorption. An example of a growth factor that is beneficial when absorbed locally and detrimental when absorbed systemically is epidermal growth factor (EGF), where its cutaneous absorption can stimulate epithelial regeneration, fibroblast migration and keratinocyte dedifferentiation, but its systemic absorption can result in enhanced growth of existing tumours [60]. A large variety of different growth factors exist as a way for the body to tailor the specific development of different bodily aspects, however for the purposes of this review, the focus will be on the specific growth factors associated with cutaneous regeneration.

As shown in Table 1, such cutaneous growth factors are necessary for wound regeneration, whereby the process of topical application can increase the concentration of such factors beyond the natural output generated by the body, thus increasing the rate of wound healing. For such reasons, platelet rich plasma (PRP) have been researched as they contain a variety of growth factors needed to accelerate wound healing. Another reason for the increasing interest 
in PRP follows its ease of obtainability and low cost, which requires the simple procedure of centrifuging a patient's blood sample, separating the blood into different layers of density with poor-platelet plasma being the lightest, which is discarded, then the PRP which is kept and finally the red blood cells which are most dense at the bottom of the centrifuge tube. Despite the various benefits, PRPs lack a standardised production protocol, leading to variations in product quality and content which occur as a result of negligible analytical characterisation. In spite of such problems, the general consensus reports an overall positive impact of PRPs in wound regeneration, especially in the case of human chronic wounds such as diabetic ulcers [78].

Growth factors represent a key target for enhancing cutaneous repair, however naturally derived compounds also serve as a viable alternative for improving cutaneous regeneration and are also relatively accessible, Table 2 . These naturally occurring substances have shown positive results in regard to enhancing wound regeneration and as of such have received attention in terms of their research and development. Despite the successes associated with these naturally derived compounds, characterisation of the active therapeutic ingredient can be difficult, especially in the case of naturally derived sources that contain a vast quantity of substances which may be therapeutically active. Such an example would be aloe vera which is composed of oxidases, amylases, catalases, oxidases and minerals including calcium, copper, chrome, magnesium, zinc, vitamins B1, B2, B6, C and E [90].

Overall the inclusion of such regenerative substances can be seen as a supplementary method for enhancing the natural regenerative capabilities of the body. By understanding the specific roles played by each growth factor, alterations can be made to specific healing mechanisms, thus improving the quality of regeneration via the increased supply of a specific growth factor, or by the inhibition of a specific factor, i.e. inhibition of Interleukin-1 to increase the upregulation of M2 macrophage for improved healing. The complementary supply of additional growth factors will typically increase the rate of recovery by decreasing the duration of time spent within a certain regenerative phase, however the maturation phase can span between 3 weeks to 12 months [91] and it is this phase which determines the final outcome of the scar produced by the wound healing process.

\subsection{Scar formation and Scar free healing}

Scar tissue exists as a product of several predetermined biophysiological mechanisms that are innately triggered as a result of wounding, followed by the subsequent recovery phase which produces a tissue that is primarily composed of fibrillar collagen generated by the myofibroblasts. The initial wound healing mechanism that contributes to the lack of elasticity in scar tissue is the maximal upregulation of fibroblasts, coupled with the formation of randomised collagen matrices that occur during the proliferation phase. Another contributing factor follows the inward proliferation of keratinocytes from the inner periphery of the wound area, resulting in a wound matrix without an elastic fibre network [92]. The maturation phase also contributes greatly towards to the outcome of the scar tissue, whereby the mechanisms leading to fibroblast reduction, coupled with collagen matrix production and degradation ultimately determine the final physical parameters of the scar.

Other factors affecting scar formation include the area in which the wounding event occurred and its associated skin tension. The occurrence of laceration wounds in areas of high skin tension will lead to further tears at the periphery, leading to increased collagen deposition thereby resulting in a hypertrophic response which creates aesthetically unwanted hypertrophic scars [93]. Areas of the body that are susceptible to such hypertrophic scarring include the areas of skin covering the extensor joints, which include area above the shoulders, knees, forearms, 
phalanges etc. Conversely speaking areas that are under the least tension have the lowest chance hypertrophic scar formation. The actual mechanism of hypertrophic scarring exists as a by-product of certain genetic or environmental factors which interfere with the signalling cascade associated with collagen synthesis, preventing the activation of the "stop" signal, which results in a positive feedback loop leading to continual collagen synthesis. This process of continual collagen synthesis within the bounds of the wound perimeter is classified as a hypertrophic scar, which is also characterised by raised scar tissue that can regress over time. The continual production of collagen beyond the scope of the wound area is classified as a keloid, which unlike its hypertrophic counterpart, does not regress with time and can be characterised by thick nodular bundles of collagen [94].

Another parameter that affects the quality of scar formation include the density of blood supply, whereby a richer blood supply leads to a higher quality scar. The absence of an adequate blood supply can negatively impact the recovery speed and quality of regeneration, as the lack of a good blood circulation can result in the deterioration of the regeneration process leading the formation of chronic wounds. This simply follows the hierarchal organisation of the cutaneous tissue, whereby the epidermal layer does not have its own blood supply, instead relying on the transportation of nutritional substrates by diffusion through the dermal-epidermal junction. In a situation where the dermal blood flow is significantly reduced, the supply of the necessary growth factors will be below the demand threshold, leading to extended periods of time spent within the regenerative phase, which result in delayed cutaneous repair.

To understand the necessary prerequisites needed to achieve scar free regeneration, it is vital to understand the processes of foetal wound regeneration which does not follow the conventional four steps of standard adult wound repair. Unlike its conventional counterpart, foetal wound regeneration does not form any scar tissue, does not involve the contraction of wounds, does not form granular tissue and does not result in the accumulation of ECM. Another big contrast is that foetal regeneration restores lost follicles and sweat glands unlike adult cutaneous regeneration [95]. Since foetal wound regeneration restores the area of injury to its pre-injured state, it can be considered a form of true regeneration as the original functions and properties of the cutaneous architecture are restored. The key discrepancies regarding the mechanisms that result in the specific restorative capability of foetal regeneration follows the differences in cellular response and its associated release of growth factors. Adult wound regeneration relies on the stimulation of the mature immune system to upregulate the appropriate cells such as macrophages, mast cells and neutrophils which contribute to scarring, however its foetal counterpart, with a less developed immune system, does not upregulate these specific cells to the same degree. Within the foetal system, these cells are also less differentiated, which when coupled with their reduced numbers, do not produce the same level of causative efficacy when compared to the adult system. The production and retention of the proinflammatory cytokines IL-6 and IL- 8 are also quite different between adult and foetal regeneration, where both cytokines are retained for a significantly shorter period of time in the foetal stage than in the adult stage. Conversely the upregulation of the anti-inflammatory cytokine IL-10 is higher and further retained in foetal regeneration which prevents the intrusion of macrophages and neutrophils, thus inhibiting the formation of scars. This is also further emphasised by the difference in the nature of the physiological response undertaken by both adult and foetal wound processes, whereby the contraction of wounds is absent within foetal regeneration. Unlike its adult counterpart, foetal systems do not heavily upregulate positive smooth muscle actin alpha, which is needed for the contraction of myofibroblasts, therefore resulting in non-existent wound contraction. Within the foetal regenerative process, the natural characteristics of the upregulated fibroblasts are different from their adult counterparts. Foetal fibroblasts not only migrate faster towards the wound area than their adult counterpart, but also 
produce an ECM that has the architecture and tensile strength comparable to that of developing skin [96]. This foetal ECM has a different compositional structure compared to its adult equivalent, where the levels of collagen III and hyaluronic acid are significantly higher. In the adult ECM, collagen III only comprises of $10-20 \%$ of the total collagen population, however within the foetal ECM, collagen III represents $30-60 \%$ of the total collagen population. Other differences between adult and foetal wound regeneration include the upregulation of proteins associated with cellular adhesion, which include fibronectin and tenascin, which accelerates the migration of reparatory cells leading to scar free regeneration.

\section{Polymeric wafers in wound management}

Polymers have been heavily researched as both a scaffolds for regenerative medicine and for the purposes of drug release. For the aspect of wound regeneration, there are a variety of different prerequisites that need to be met before the polymer can be taken into consideration as a candidate. Such requirements include the need of high biocompatibility, good photo and thermal stability, non-cytotoxic pre and post degradation, structurally adequate and most importantly needs to be fit for purpose. In terms of the current applications of polymers within the field of regenerative medicine, various different aspects have been explored, including the aspect of antimicrobial applications, where polymer wafers are doped with nano-metals to form a polymer-nano-metal composite. One of the most popular composites is the nanosilver polymer composite which has been reported to have high antibacterial performance [97-99], other well reported antimicrobial nano-metal polymer composites include copper [100-102] and gold $[103,104]$. Other aspects of polymer usage include its application in wound healing [105]. In the aspect of wound healing, the priority of large-scale polymer architectures is for the maintenance of a suitable environment that can facilitate enhanced healing, modulation of wound biomechanics, whilst providing protection from contaminations and infections. For this reason, different factors such as gas permeability, porosity, fluid absorption capacity and density need to be accounted for, as they will affect the ability of a large-scale polymer structure to effectively retain the optimal conditions for wound healing.

\subsection{Types of polymers}

\subsubsection{Natural polymers}

Natural polymers are generally well considered for their use in biomedical applications as their innate characteristics do not typically stimulate any disadvantageous immunological responses and do not produce any cytotoxic metabolites as a result of degradation. Whilst these advantages are highly regarded, the natural properties of such polymers also pose a limit in regard to their process-ability and solubility, leading to problems associated with to low thermal stability and high solubility when compared against their synthetic counterparts. Despite such problems, natural polymers are frequently used in the application of bioactive wound dressings which take advantage of the natural polymer's role within the body's biomechanics, thereby improving the efficiency of wound regeneration, as well as helping to incorporate varying degrees of antimicrobial effect. As depicted by the various properties, advantages and disadvantages listed in Table 3, the overall physiological effects are positive in general, thus leading to their specific usage within wound healing applications such as wound dressing and drug delivery. 
This is a peer-reviewed, accepted author manuscript of the following research article: Man, E., \& Hoskins, C. (Accepted/In press). Towards advanced wound regeneration. European Journal of Pharmaceutical Sciences.

\subsubsection{Synthetic Polymers}

Synthetic polymers designed for wound healing are generally hydrophobic but are chemically and mechanically superior to their natural counterparts, leading to extended viability as a result of high durability coupled with reduced rates of degradation. Synthetic polymers dressings for wound regeneration can be categorized into passive and interactive types, whereby passive polymer dressings are non-occlusive in nature allowing the possible penetration of pathogens, however the main function of the passive dressing is to simply restore function to the wound beneath the dressing. On the contrary, interactive dressings are fully occlusive or semiocclusive, thereby proving protection in the form of a physical barrier that prevents pathogenic penetration [122]. The advantages of using semi-occlusive dressings follow the semipermeable nature of the polymer macrostructure, allowing for the gaseous transfer of oxygen, carbon dioxide and water vapour, which creates an environment that supports the engagement of autolytic debridement. Autolytic debridement follows the selective lysis of damaged tissue by the secretion of immunological enzymes which do not affect healthy tissue and is generally most effective when the environmental humidity is high, thus requiring fully/semi-occlusive dressings [123]. In spite of the various benefits provided by synthetic polymers, the majority are seldom used by themselves and are instead combined with other synthetic or natural polymers to produce a composite that is superior to its constituents. The main synthetic polymers used are poly(ethylene glycol) [124-126], poly(vinyl alcohol) [127-129], poly(vinyl pyrrolidone) $[130,131]$, poly(lactic acid) $[132-134]$, poly- $\varepsilon$-(caprolactone) $[132,135,136]$ and poly(urethane) $[137,138]$.

Comparison between both synthetic and natural polymers, indicate that synthetic polymers offer superior physical characteristics and significantly higher tensile strength, leading to decreased rates of degradation and increased thermal stability. Despite having superior physical properties, they are generally less biocompatible than their natural counterparts and display a hydrophobic nature which is the opposite of natural polymers. Natural polymers on the other hand offer superior biocompatibility, coupled with bioactive characteristics as the breakdown of specific natural polymers are beneficial in enhancing the proliferative efficacy of the body, i.e. HA and collagen. The main disadvantage when compared to synthetic polymers is the fact that they are generally weaker in terms of their mechanical strength and their stability, thus leading to higher rates of degradation. The creation of synthetic-natural composite polymers typically alleviates the disadvantages posed by the constituent polymers, whereby the composite can be created in such way that only the beneficial characteristics are imparted from the constituents, leading to a product with superior mechanical and biological properties. In specific examples such as PLA, its excessive mechanical strength result in it being brittle, so by combining it with other polymers, the properties leading to brittleness are diluted down, thus only imparting the beneficial mechanical advantages without the presence of any notable drawbacks. In most cases, the creation of hybrid polymers requires an optimal ratio of natural-synthetic polymer constituents, which allows the biophysical properties of the resulting matrix to be fine-tuned for to its intended application. While the biomedical utilization of both natural and synthetic polymers as wound dressings is undoubtable, one inherent issue is its scalability towards mass manufacturing. As these wound dressings are designed for biomedical purposes, the quality requirements must be highly stringent, which leads to a variety of challenges that need to be met prior to mass production. In terms of quality assurance, the main issues revolve around the initial sourcing of the reagents at the input stage, followed by the synthesis stage and the output stage. The initial sourcing of reagents generally dependent on the supplier, whilst the synthesis and output stage lies with the manufacturer. In both instances rapid screening of the material is necessary to ensure that the product reaches a satisfactory level of quality. Although this generic requirement can be applied towards all wound dressing manufacturing processes, certain polymers such as poly(ethylene glycol) require cytotoxic cross linkers, leading to additional screening stages for the presence of cytotoxic compounds in the synthesis and output stage. Failure to meet such stringent standards can lead to the recall of the products 
from the public, which not only causes socioeconomic distrust and financial loss, but can also lead to cytotoxicity induced pathologies. Following the mass recall of defective products, the next stage may involve the readjustment of the manufacturing process, which is an extremely difficult due to the inherent inflexibility of the manufacturing system to adapt to changes in its intrinsic processes. Depending on the changes that need to be applied, the economic burden can range between a minor loss in annual revenue to the complete liquidation of the manufacturing company. Adjustments to the early stages of the manufacturing process have the largest cumulative effect on the manufacturing system, which may result in changes in the synthesis processes and reagents used, thereby leading to the greatest loss in revenue. Adjustments towards to later stages in the manufacturing process may simply require minor adjustments in its screening process, thereby resulting in the most minor loss in revenue. It should be stated that the set up and development of the mass production infrastructure needed is generally extremely expensive, so it is therefore necessary to minimise the total manufacturing stages where possible and to have developed a synthetic process with minimal room for error.

\subsection{Polymer synthesis methods}

Different methodologies exist for the fabrication of large three-dimensional polymer constructs, allowing for alterations to be made in regard to the construct's physical characteristics and properties. Specific fabrication methods are utilised to imbue a certain set of desired characteristics into the polymer construct, thus creating a structure with a dedicated purpose. Regarding the choice in methodologies, some techniques are significantly more advantageous than others, potentially revolving around the factors of cost, ease of application, product cytotoxicity and the controllability over the parameters of the final product. The selection criteria for the most optimal synthetic method is influenced by the limiting factors that are established in regard to the desired parameter of the end product. An example of this would be the fact that non-cytotoxic product will typically not utilise any solvents that can affect negatively influence the biocompatibility and surface chemistry of the polymer construct. As the methodology needs to be tailored to the parameters associated with the end product, certain compromises are necessary to facilitate the successful fabrication of the desired product, leading to the potential use of high maintenance equipment, post-process wash steps to cleanse the product of toxic solvents and by products, or perhaps post-process surface modifications to adjust the biocompatibility and hydrophilicity to the necessary levels. The factors that determine the choice in fabrication methods include the controllability over the pore size, pore density, polymer density, the hydrophobic/hydrophilic characteristics, biocompatibility, cytotoxicity, mechanical strength, matrix characteristics, etc. Based on these factors, a synthetic method can then be chosen to best suit the characteristics of the final polymer product. These techniques include freeze drying [139], solvent casting [140,141], supercritical foaming [142,143], electrospinning [144-146], laser induced thermal gelation [147], 3D bio printing [148] chemical crosslinking [149,150] or physical crosslinking [150]. Each of which have their own discrete advantages and disadvantages which can be considered based on overall polymer requirements.

\subsubsection{Polymer composites}

The range of biophysical characteristics offered by synthetic and natural polymers are vast, however certain characteristics such as antibacterial activity are generally isolated to only a handful of specific polymers and does not generally manifest itself in the latter. To counteract this limitation, polymer composites were developed which allowed the imbuement of characteristics from the constituent polymers into the final multi-polymer structure. Typically speaking, natural polymers are blended with synthetic polymers to maximise the biocompatibility and physical properties which generally increases the efficacy of the 
composite polymer. However, unlike non-composite polymers the synthetic methods are more complex and requires significant fine tuning to manifest the appropriate characteristics at the correct level. Different structural combinations can exist, ranging from a composite with alternating monomer units, a composite with a randomised monomer structure, a composite with a distinct homopolymer chain, etc. A variety of different methods exist for the synthesis of composite polymers, whereby each method produces a distinct polymer combination that allows for the manifestation of certain effects that can only attributed to structural configuration of the polymer blend. These include interpenetrating networks [151,152], semi-interpenetrating networks [153-155], graft polymerisation [156,157], and electrospinning [158,159].

\subsection{Drug loading methods}

To maximise the medical efficacy of polymer products, drugs and other pharmaceutical compounds can be loaded into the polymer where it can then be released in a controlled and localised manner. Variations in the synthetic method can affect the final structure of the polymer matrix which ultimately determines the maximal loading capacity, as well as the drug release profile. Drug delivery systems typically follow three main loading methods which include covalent bonding, entrapment and permeation. Covalent bonding revolves around the covalent and physical cross-linking of the drug molecule onto the matrix structure of the polymer. The advantages offered by this method include the prevention of premature drug release and leakage, stimuli-triggered drug release and modifiable drug pharmacokinetics [160]. Entrapment revolves around the encapsulation of drug molecules via the gelation of the polymer matrix. The advantages offered by this method include sustained drug release capabilities and drug protection from external conditions [161]. Drug loading via permeation involves the passive saturation of the polymer matrix with the drug solution over an extended period of time. This extended period of permeation ensures the maximal saturation of polymer matrix but does not allow any form of control over the drug release profile. The main benefit of this method is the simplicity of drug loading, however since the drug release profile is uncontrollable, it is therefore unable to perform the sustained release of drug molecules. Other factors that affect the loading and release of drugs via polymer delivery include the size of the drug compound, polarity, the hydrophobic nature of the polymer and the synthetic method used to create the polymer, which governs the pore size and distribution.

\section{Priorities for efficient skin regeneration}

The general consensus regarding the key factors that contribute towards effective skin regeneration revolve around the aspects of antibacterial strategies, enhanced regeneration, control over the inflammatory phase, maintaining the skin's moisture content and the regulation of the scarring process. Each of these various aspects offer a unique set of advantages that either help to facilitate the rate of healing, provide long term benefits or serve to enhance the quality of regeneration.

\subsection{Antibacterial strategies}

Antibacterial strategies serve as an inhibitory method for the prevention of bacterial proliferation and respiration. Inhibition of such activities help to not only reduce the total bacterial population but serve to drastically reduce the production of metabolic waste which can be cytotoxic depending on the bacterial strain. In general, the most efficient antibacterial methods are bactericidal in nature, as this not only prevents bacterial activity, but induces apoptosis or cell lysis. The most common method of inducing apoptosis follows the process of oxidative stress which occurs as result of the imbalance in the quantity of free radical species 
within the bacterial body. Once the intake rate of free radicals exceeds the rate of release, the equilibrium shifts, resulting in the accumulation of free radicals that result in oxidative damage to the organelles within the bacteria. This then leads to self-induced apoptosis, which is a genetically driven form of self-preservation, thus preventing the proliferative distribution of damaged genetic material [162]. Cellular damage via free radical oxidation is a highly prominent antibacterial strategy for topical biocides such as hydrogen peroxide and nanometals.

The incessant proliferation of bacteria within the confines of a wounded area can lead to the development of chronic wounds, which occurs as a result of continual inflammation. Persistent bacterial activity within the wound can lead to the accumulation of lipases and proteases which degrades the ECM, allowing the bacterial populace to penetrate further into the lower dermal layers. The subsequent increase in the spread of bacteria then triggers the immune response again, which further exacerbates the inflamed tissue, leading to a state of chronic inflammation which in itself can impair the facilitation of the healing phase. The inherent nature of chronic wounds not only imply the problem of diminished healing, but also the impairment of functionality for tissues and organs around its vicinity. The chronic cytotoxicity of the pathogens present in the wound is a summation of their biological processes, which include their excretions and by-products. Generally speaking, these by-products serve to increase the permeation and spread of the pathogen by enzymatically breaking down the structural proteins between surrounding tissues [16]. Infections can also damage surrounding structures within the wound such as the nerves which can cause neuropathy and may also reach deep enough to infect the underlying blood vessels resulting in sepsis. In regards to the physiological sensitivity of chronic wounds, it highly is dependent on the initial occurrence of the wound. Superficial wounds may lead to the exposure of nerve endings towards the external environment, however subcutaneous occurrences such as diabetic foot ulcers lead to neuropathy which damages the nerve endings, thus reducing overall sensitivity [163]. In the case of chronic skin wounds originating from a neuropathic subcutaneous origin, the patient may not realise the extent of the injury that has occurs. As of such once the visible signs of damage have surfaced on the skin, the underlying subcutaneous tissue may have already degenerated significantly, leading to the requirement of a more intensive treatment. On the contrary chronic wounds caused by external stimuli are generally more noticeable given the fact that they begin as an acute skin wound. The acute wound is generally more visible and have exposed nerve endings which gives the patient the visual and physiological stimulus needed to seek an appropriate treatment. Should the acute wound be diagnosed and treated appropriately, then it will not degenerate into a chronic wound, thus not requiring any further intensive treatments.

The most common pathology associated with chronic wounds is sepsis, which occurs as a result of the bacterial colony penetrating through the dermal defences and into the blood stream, consequently leading to the migration of the bacterial populace throughout the body. This in turn leads to a large-scale immune response, causing full body inflammation and severe chemical imbalance throughout the body, which altogether can result in organ failure and death. Therefore, by prioritising the development of antibacterial strategies, such problems can be alleviated allowing the body to reallocate its resources to regeneration as opposed to inflammation.

\subsection{Accelerated regeneration}

Strategies associated with enhanced regeneration typically involve the augmentation of the proliferative phase and/or the maturation phase to promote increased rates of wound closure, as well as help to improve the overall quality of healing. Such strategies work by triggering the activation of growth factors associated with wound healing such as EGF, TGF- $\beta$, and bFGF 
etc., which serve to stimulate the proliferation and migration of dermal cells for the purposes of re-epithelization. The speed of regeneration is a highly regarded aspect of wound healing as it minimises the duration of the proliferative phase, thus reducing the exposure of deeper more vascularised tissue, which if infected can quickly lead to the distribution of bacteria throughout the body. On the other hand, the quality of regeneration revolves around the maturation phase, which primarily follows the remodelling of the collagen matrix to achieve maximal tensile strength and the restoration of original function where possible. Unlike the proliferative phase which ends once the wound surface is covered by a keratinocyte monolayer, the remodelling phase is substantially longer, involving the continual degradation of randomly aligned collagen III, followed by its subsequent replacement with organised collagen I. The replacement collagen I molecules then align themselves in a parallel manner to form thicker more organised fibres thus increasing the tensile strength and elasticity whilst reducing the overall quantity of scar tissue. For the purposes in accelerating the speed of regeneration and the prevention of wound degradation, it is also necessary to ensure an adequate blood flow around the affected area as this will serve to transfer the necessary nutrients needed for enhanced proliferation and to removal any metabolic waste that is produced.

\subsection{Controlling the inflammatory phase}

The inflammatory phase represents the second stage of wound healing after the haemostasis phase and is associated with the elimination of pathogens as well as the influx of biological components needed for wound closure and angiogenesis [164]. This particular phase is of great physiological importance to the maintenance of cellular tissue as it assists in the removal of impaired cells, cellular debris, tumour cells and pathogens, thus providing the necessary foundation for the facilitation of enhanced regeneration. Despite its biological significance, the dysfunction of the inflammatory phase can occur, resulting in occurrence of damage to healthy tissue which can be attributed to the production of excess leukocytes. Such dysfunction is generally associated with the overexpression of IL- $1 \beta$ which polarises the upregulation of the M1 macrophage phenotype. This specific phenotype is of a proinflammatory nature, whereby its main function is the rapid elimination of damaging biological matter but can also result in significant collateral damage if its active population is not kept in check. The standard physiological procedure after the production of M1 macrophage phenotype is the downregulation of IL-1 $\beta$ which upregulates the activity of peroxisome proliferator activated receptor $\gamma$ [165]. The upregulation of this receptor's activity helps to facilitate the transition of the M1 phenotype into the M2 phenotype, which is associated with healing unlike its phenotypic counterpart, however this M2 phenotype can also promote the occurrence of cancer [166]. Inflammatory dysfunction can occur due to the failure of the immune system to express the cytokines associated with inflammatory resolution such as IL-10, thus resulting in continued inflammation [167]. This then leads to the uncontrolled, continual upregulation of IL-1 $\beta$ which facilitates the overproduction of the M1 phenotype without the occurrence of the M2 transition process, thereby resulting in the accumulation of M1 macrophages. This then contributes towards the impairment of tissue repair, subsequently leading to the occurrence of chronic inflammation [168]. To maximise the overall efficacy of the wound healing process, the optimal regenerative strategy must influence the inflammatory phase in such a way that the duration of inflammation is kept to a minimum, thus facilitating the fastest possible occurrence of the post-inflammatory wound healing process.

\subsection{Maintenance of dermal moisture}

Dermal moisture serves a variety of purposes, such as the maintenance of intracellular osmolarity which allows for the occurrence of regular intracellular biological activity, intercellular transport and signalling, skin barrier function etc. In the context of skin 
regeneration, the retention of dermal moisture helps to facilitate autolytic debridement, reduces the chance of cutaneous irritation, prevents desquamation, maintains the osmotic state needed for full barrier function to occur etc. The regulation of dermal moisture content is dependent on two main factors, which are the presence of innate dermal hygroscopic agents and arrangement of intercellular lipids in the SC for the prevention of transdermal water loss. The reduction of dermal moisture below the critical physiological level can lead to the initiation of various cutaneous pathologies. This occurs as a result of the impairment of enzymatic activity which leads to the aggregation and adhesion of corneocytes, subsequently leading to transdermal water loss (TDWL) and the impairment of dermal barrier function. It is widely accepted that both TDWL and barrier function are regulated by the presence of intracellular lipids that occur within the tight junctions between the cornified cells of the SC, which organises itself in a layer like manner thus acting as a physical barrier [169]. This lipid barrier can be impaired by elevated temperatures which can disrupt the arrangement of the SC lipids, thereby leading to the occurrence of TDWL [170]. An important factor that needs to be accounted for regarding the integrity and susceptibility of the SC lipid barrier is the fact that seasonal variations in SC lipid levels can occur. Such seasonal variations can influence the production rate of SC lipids, whereby the total production of SC lipids is significantly greater during summer than that of spring and winter [171].

Taking these facts into account, it is therefore necessary to implement a hydration-based strategy that can help to maintain the SC lipid level, increase the quantity of innate hygroscopic compounds and to reverse the adhesive agglomeration of corneocytes if possible. Not only will this help adjust the innate osmotic levels of the epidermis to its correct physiological level, but it will also help to facilitate cellular proliferation and intercellular transport for effective dermal regeneration.

\subsection{Regulating the scarring process}

Scars initially occur as a product of the proliferative phase, where the ECM is largely unorganised with suboptimal mechanical properties but is adequate enough to prevent pathogenic penetration. The development of scar tissue is generally positive in terms of its physiological role in wound healing, however for specific cutaneous regions, the replacement of native tissue with scar tissue can cause functional problems relating to the organs and articular regions that the native tissue covers. An example of this would be in extensor joint areas such as the elbows and knees which are covered by skins fold that allow the joints to extend without causing extreme tensile stress on the skin. If a significant portion of the skin fold is replaced by scar tissue, then the maximum mobility of the extensor joints will be greatly diminished, thus significantly affecting the patient's quality of life. As scar tissue lacks the elastic potential of most native skin tissue, excessive tensile strain can cause the scar to rupture, leading to further cases of infection and medical complications. From a psychological perspective, the scarring process is necessary for the maintenance of the patient's health, however from a psychosocial standpoint the degree of cutaneous scarring can also lead to many problems. The process of scarring itself causes hyperpigmentation to occur which is a byproduct of excess melanocyte activation, leading to the increase in melanin production and its subsequent uptake into the surrounding tissue. The occurrence of cutaneous scarring and hyperpigmentation in visually exposed areas can lead to cases of societal stigma, hostility and rejection, thus resulting in the development of social withdrawal problems and the degeneration of the patient's mental health [172]. Overtime the psychological burden placed on the patient can cause them to become socially dysfunctional, which not only severely reduces the quality of life, but can also result in the need of interventions to help the patient adjust back into society. 
This is a peer-reviewed, accepted author manuscript of the following research article: Man, E., \& Hoskins, C. (Accepted/In press). Towards advanced wound regeneration. European Journal of Pharmaceutical Sciences.

As of such, being able to regulate the scarring process will help to prevent the occurrence of psychosocial problems for the patient and will also help to reduce the strain on the resources necessary for societal readjustment.

As discussed previously, the maturation phase of the wound healing process gradually reorganises the biological constituents of the scar through degradation and resynthesis to produce an ECM with mechanical properties that more closely resemble the original tissue architecture than the scar tissue. Despite the physiological significance of the scarring process in the restoration of tissue function and mechanical strength, there are still many negative aspects associated with it, such as the fact that scar remodelling process can take up to several months, dermal discolouration, the fact that only a maximum of $80 \%$ tensile strength can be restored [173], reduction in elasticity, as well as the social stigma that is associated with aesthetic dermal imperfections.

To achieve the optimal hypothetical result, the aims of the regenerative strategy should focus primarily on the maximal recovery of lost tissue function, elasticity and tensile strength which will ultimately determine the quality of regeneration. Although there are many factors that can dictate the maximal recovery potential of a scar, i.e. age, skin tension and wound size, one possible strategy that could be viable may encompass the use of topographical cues to promote the enhanced alignment of collagen and fibroblasts, thus improving the quality of the scar [174].

\section{Conclusions and Future Outlook}

To develop an effective strategy for wound healing, it is first necessary to understand the cutaneous architecture, the natural mechanism of wound regeneration and the various pathologies that stem from physical insult. Each of these subject areas can offer valuable insight in terms of the necessary objectives that are required for achieving maximum regeneration. By understanding these subject areas, it is possible to determine the type of antibacterial strategy that is needed to prevent a pathological cascade, whilst choosing the optimum type of regenerative strategy to aid the body's natural healing processes for enhanced wound closure. Various factors can affect the regenerative potential of a wound, such as the area of injury, severity of injury, type of injury, patient age, hormone levels, diabetes, patient health and the presence of systemic medication etc. Whilst it is difficult account for every possible factor, as long as the general understanding of the causative pathology is sufficient, then it is possible to develop a baseline regenerative strategy that can be applied to most dermal wounds.

The current development of technologies that can be attributed to wound healing are vast and remarkable, with some showing strong indications for clinical use in the foreseeable future. Despite the noteworthy advancements that have been made, the general research pathway seems to be relatively narrow and linear in nature, displaying remarkable success in very concise areas of research. Although this is not a negative convention by any means, there is a general lack of experimental research that brings together the cumulative knowledge from different fields in an attempt to answer the questions posed by the bigger picture. Taking the topic of wound regeneration as an example, it can be separated into a variety of subtopics including antibacterial strategies, enhancing the speed of regeneration, revascularisation and drug delivery strategies etc. Although each of these subtopics have received a significant amount of development, there is no specific study that includes the summative findings of these subtopics into the final outcome. Although it can be speculated that such a study will be too broad, therefore requiring extended periods of time to cover all of the various parameters; it will however fill in the knowledge gap that exists in terms of the possible interactions that can 
occur between certain aspects of each subtopic area. In the case of wound regeneration, where the outcome could be a multifunctional polymer wafer for antibacterial and regenerative purposes; it would therefore be appropriate to identify the nature of the interactions that may occur between the substances which represent the antibacterial aspect, the regenerative aspect and the polymer matrix itself. By identifying these specific interactions, it would be therefore be possible to deduce whether each specific interaction is of a synergistic or discordant nature, thereby allowing the product to be fine-tuned, thus maximising the cumulative efficacy of the final product. Other reasons for determining the nature of the interactions include the prevention of possible cytotoxic by-products that may occur, possible reductions in the efficacy of certain aspects such as the reduction in antibacterial effect and the possible degradation of the polymer matrix as a result of the by-products produced from the interaction of regenerative and antibacterial substances. The findings produced from such research are expected to be quite significant in terms of their clinical relevance and as of such need to be explored. This will help to establish a foundational guideline in which multi-regenerative applications of the future must adhere to for the purposes of clinical reliability.

To produce a feasible regenerative product for wound healing as a whole, the three main subtopics that must be explored are antibacterial strategies, wound healing enhancements and the type of medium that is used substance delivery. Each of these subtopics represent a large area of study within the field of wound regeneration, with each subtopic offering a different variety of solutions for a specific aspect of wound healing. Based on this fact, it is therefore necessary to explore the different combinations of technologies which exist within the field of wound regeneration, as this will facilitate the development of more effective therapies or interventions.

\section{Author Credit}

EM wrote the article draft under supervision and guidance of $\mathrm{CH}$. Both authors approved the final article before submission.

\section{References}

1. J.B.Shah, Journal of the American College of Certified Wound Specialists, The History of Wound Care. 2011; 3: 65-66

2. JCN, Reality of wound care in 2017: findings from interactive voting pads. 2018; 32(1): 56-61

3. J.F.Guest, K.Vowden, P.Vowden, Journal of Wound Care, The health economic burden that acute and chronic wounds impose on an average clinical commissioning group/health board in the UK. 2017; 26(6)

4. K.Ousey, K.Edward, Healthcare, Exploring Resilience When Living with a Wound An Integrative Literature Review. 2014; 2: 346-355

5. C.Dessinioti, A.D.Katsambas, Clin. Dermatol, The role of Propionibacterium acnes in acne pathogenesis: facts and controversies. 2010; 28: 2-7

6. E.A.Grice, J.A.Segre, Nat Rev Microbiol, The skin microbiome. 2011; 9(4): 244-253

7. M.H.Braff, A.Bardan, V.Nizet, R.L.Gallo, J. Invest. Dermatol, Cutaneous defense mechanisms by antimicrobial peptides. 2005; 125: 9-13

8. G.J.M.Christensen and H.Brüggemann, Beneficial Microbes, Bacterial skin commensals and their role as host guardians. 2014; 5(2): 201-215 
9. S.C Costigan, P.J.Booth, R.H.Templer, Biochim. Biophys Acta, Estimations of lipid, bilayer geometry in fluid lamellar phases. 2000; 1468: 41-54

10. S.Mitragotri, Journal of Controlled Release, Modeling skin permeability to hydrophilic and hydrophobic solutes based on four permeation pathways. 2003; 86: 69-92

11. P.Schlupp, M.Weber, T.Schmidts, K.Geiger, F.Runkel, Results in Pharma Sciences, Development and validation of an alternative disturbed skin model by mechanical abrasion to study drug penetration. 2014; 4: 26-3

12. L.V.Simon, M.F.Hashmi, K.C.King, Treasure Island (FL), StatPearls Publishing, Blunt Force Trauma. 2019 Jan

13. Hess, C.Thomas, Advances in Skin \& Wound Care: The journal for prevention and healing, DID YOU KNOW? The Difference between Friction and Shear. 2004; 17(5): 222

14. V.K.Tiwari, Indian J Plast Surg, Burn wound: How it differs from other wounds? 2012; 45(2): 364-373

15. F.Ma, Clin Case Rep, Accumulative eschar after burn. 2016; 4(2): 151-153

16. Y.Hanakawa, N.M.Schechter, C.Lin, K.Nishifuji, M.Amagai, J.R.Stanley, J Biol Chem, Enzymatic and molecular characteristics of the efficiency and specificity of exfoliative toxin cleavage of desmoglein 1. 2004; 279: 5268-5277

17. T.Ohbayashi, A.Irie, Y.Murakami, M.Nowak, J.Potempa, Y.Nishimura, M.Shinohara, T.Imamura, Microbiology, Degradation of fibrinogen and collagen by staphopains, cysteine proteases released from Staphylococcus aureus. 2010; 157: 786-792

18. J.H.Yang, P.Bhargava, D.McCloskey, N.Mao, B.O.Palsson, J.J.Collins, Cell Host \& Microbe, Antibiotic-Induced Changes to the Host Metabolic Environment Inhibit Drug Efficacy and Alter Immune Function. 2017; 22: 757-765

19. E.Y.Klein, T.P.V.Boeckel, E.M.Martinez, S.Pant, S.Gandra, S.A.Levin, H.Goossens, R.Laxminarayan, PNAS, Global increase and geographic convergence in antibiotic consumption between 2000 and 2015. 2018; 115(15): 3463-3470

20. S.X.Wang-Lin, J.P.Balthasar, Antibodies, Pharmacokinetic and Pharmacodynamic Considerations for the Use of Monoclonal Antibodies in the Treatment of Bacterial Infections. 2018; 7(5)

21. G.A.Sotiriou, S.E.Pratsinis, Curr Opin Chem Eng, Engineering nanosilver as an antibacterial, biosensor and bioimaging material. 2011; 1(1): 3-10

22. G,V.Vimbela, S.M.Ngo, C.Fraze, L.Yang, D.A.Stout, International Journal of Nanomedicine, Antibacterial properties and toxicity from metallic nanomaterials. 2017; 12: 3941-3965

23. A.K.Chatterjee, R.Chakraborty, T.Basu, Nanotechnology, Mechanism of antibacterial activity of copper nanoparticles. 2014; 25(13)

24. I.M.Sadiq, B.Chowdhury, N.Chandrasekaran, A.Mukherjee, Nanomedicine: Nanotechnology, Biology and Medicine, Antimicrobial sensitivity of Escherichia coli to alumina nanoparticles. 2009; 5(3): 282-286

25. S.Pasupathy, M.Rajamanickam, IJPSR, SYNTHESIS OF PURE AND BIO MODIFIED CALCIUM OXIDE (CaO) NANOPARTICLES USING WASTE CHICKEN EGG SHELLS AND EVALUATION OF ITS ANTIBACTERIAL ACTIVITY. 2019; 10(10): 4731-4737

26. M.Zhang, C.Zhang, , X.Zhai, F.Luo, Y.Du1, C.Yan, Sci China Mater, Antibacterial mechanism and activity of cerium oxide nanoparticles. 2019, 62(11): 1727-739

27. M.H.Toodehzaeim, H.Zandi, H.Meshkani, A.H.Firouzabadi, J Dent, The Effect of CuO Nanoparticles on Antimicrobial Effects and Shear Bond Strength of Orthodontic Adhesives. 2018 Mar; 19(1): 1-5 
28. A.J.Noori, F.A.Kareem, Heliyon, The effect of magnesium oxide nanoparticles on the antibacterial and antibiofilm properties of glass-ionomer cement. 2019; 5: e02568

29. S.Jagadeeshan, R.Parsanathan, Springer international publishing, Advanced Nanostructured materials for environmental remediation - 3. Nano-metal Oxides for Antibacterial Activity. 2019

30. H.J.Haugen, S.P.Lyngstadaas, Wound Healing Biomaterials, Antibacterial effects of titanium dioxide in wounds. 2016; $2: 439-450$

31. R.Augustine, Y.B.Dalvi, Y.Nath V.K, R.Varghesec, V.Raghuveeran, A.Hasan, S.Thomas, N.Sandhyarani, Materials Science and Engineering: C, Yttrium oxide nanoparticle loaded scaffolds with enhanced cell adhesion and vascularization for tissue engineering applications. 2019; 103: 109801

32. R.Raghupathi, R.T.Koodali RT, A.C.Manna, Langmuir, Size-dependent bacterial growth inhibition and mechanism of antibacterial activity of zinc oxide nanoparticles. 2011; 27: 4020-4028

33. S.Avvakumova, M.Colombo, E.Galbiati, S.Mazzucchelli, R.Rotem, D.Prosperi, Micro and Nano Technologies, Chapter 6 - Bioengineered Approaches for Site Orientation of Peptide-Based Ligands of Nanomaterials, Biomedical Applications of Functionalized Nanomaterials, Concepts, Development and Clinical Translation. 2018: 139-169

34. C.Musante, J.C.White, , Environ Toxicol, Toxicity of silver and copper to cucurbita pepo: differential effects of nano and bulk-size particles. 2012; 27(9): 510-517

35. Y.Sun, Y.Xia, Science, Shape-controlled synthesis of gold and silver nanoparticles. 2002; 298 (5601): 2176-2179

36. B.D.Clark, C.R.Jacobson, M.Lou, D.Renard, G.Wu, L.Bursi, A.S.Ali, D.F.Swearer, A.Tsai, P.Nordlander, N.J.Halas, ACS Nano, Aluminum Nanocubes Have Sharp Corners. 2019; 13: 9682-9691

37. A.Alshareef, K.Laird, R.B.M.Cross, Acta Metallurgica Sinica (English Letters), Chemical Synthesis of Copper Nanospheres and Nanocubes and Their Antibacterial Activity Against and sp. 2017, 30(1): 29-35

38. M.Jose, M.Sakthivel, Materials Letters, Synthesis and characterization of silver nanospheres in mixed surfactant solution. 2014; 117: 78-81

39. Z.Zhang, J.Zhang, B.Zhang, J.Tang, Nanoscale, Mussel-inspired functionalization of graphene for synthesizing Ag-polydopamine-graphene nanosheets as antibacterial materials. 2013; 5(1): 118-123

40. N.N.Mahmoud, A.M.Alkilany E.AKhalil, A.G.Al-Bakri, International journal of Nanomedicine, Antibacterial activity of gold nanorods against Staphylococcus aureus and Propionibacterium acnes: misinterpretations and artifacts. 2017; 12: 7311-7322

41. Y.Zhu, M.Ramasamy, D.K.Yi, ACS Appl Mater Interfaces, Antibacterial activity of ordered gold nanorod arrays. 2014; 6(17): 15078-15085

42. E.Yan, M.Cao, Y.Wang, et al, Mater Sci Eng C, Gold nanorods contained polyvinyl alcohol/chitosan nanofiber matrix for cell imaging and drug delivery. 2016; 58: 10901097

43. Y.Sibidou, C.Ting-Kuang, T.Shih-Hua, K.Jui-Chi, H.Po-Hsuan, S.Chen-Yen, K.Tsung-Rong, Int. J. Mol. Sci, Antimicrobial Gold Nanoclusters: Recent,Developments and Future Perspectives. 2019; 20: 2924

44. X.Yang, S.Zhu, Y.Dou, Y.Zhuo, Y.Luo, Y.Feng, Talanta, Novel and remarkable enhanced-fluorescence system based on gold nanoclusters for detection of tetracycline. 2014; 122: $36-42$

45. I.Díeza, R.H.A.Ras, Nanoscale, Fluorescent silver nanoclusters. 2011; 5

46. A.J.Frank, N.Cathcart, K.E.Maly, V.Kitaev, J.Chem. Educ, Synthesis of Silver Nanoprisms with Variable Size and Investigation of Their Optical Properties: A First- 
Year Undergraduate Experiment Exploring Plasmonic Nanoparticles. 2010; 87(10): 1098-1101

47. L.Rizzello, R.Cingolani, P.P.Pompa, Nanomedicine, Nanotechnology tools for antibacterial materials. 2013; 8: 807-821

48. C.D.Bandara, S.Singh, I.O.Afara, A.Wolff, T.Tesfamichael, K.Ostrikov, A.Oloyede, ACS Appl. Mater. Interfaces, Bactericidal Effects of Natural Nanotopography of Dragonfly Wing on Escherichia coli. 2017; 9(8): 6746-6760

49. M.Ben-Sasson, Z.R.Zodrow, Q.Genggeng, Y.Kang, E.P.Giannelis, M.Elimelech, Environ Sci Technol, Surface functionalization of thin-film composite membranes with copper nanoparticles for antimicrobial surface properties. 2014; 48(1): 384-393

50. M.Arakha, M.Saleem, B.C.Mallick, S.Jha, Scientific Reports, The effects of interfacial potential on antimicrobial propensity of $\mathrm{ZnO}$ nanoparticle. 2015; 5: Article number 9578

51. A.Kumar, C.K.Dixit, Advances in Nanomedicine for the Delivery of Therapeutic Nucleic Acids, 3 - Methods for characterization of nanoparticles. 2017: 43-58

52. S.Ghosh, V.S.Goudar, K.G.Padmalekha, S.V.Bhat, S.S.Indi, H.N.Vasan, RSC Adv, $\mathrm{ZnO} / \mathrm{Ag}$ nanohybrid: synthesis, characterization, synergistic antibacterial activity and its mechanism. 2012; 3(2): 930-940

53. M.Saliani, R.Jalal, E.K.Goharshadi, Jundishapur J Microbiol, Effects of $\mathrm{pH}$ and Temperature on Antibacterial Activity of Zinc Oxide Nanofluid Against Escherichia coli O157: H7 and Staphylococcus aureus. 2015; 8(2): e17115

54. E.Gontier, M.Ynsa, T.Bíró, J.Hunyadi, B.Kiss, K.Gáspár, T.Pinheiro, J.Silva, P.Filipe, J.Stachura, W.Dabros, T.Reinert, T.Butz, P.Moretto, J.Surlève-Bazeill, Nanotoxicology, Is there penetration of titania nanoparticles in sunscreens through skin? A comparative electron and ion microscopy study. 2008; 2(4)

55. F.F.Larese, F.D'Agostin, M.Crosera, G.Adami, N.Renzi, M.Bovenzi, G.Maina, Toxicology, Human skin penetration of silver nanoparticles through intact and damaged skin. 2009; 255(1-2): 33-37

56. H.I.Labouta, L.K.El-Khordagui, T.Krausc, M.Schneider, Nanoscale. Mechanism and determinants of nanoparticle penetration through human skin. 2011; 3: 4989-4999

57. F.F.Larese, M.Mauro, G.Adami, M.Bovenzi, M.Crosera, Regul Toxicol Pharmacol, Nanoparticles skin absorption: New aspects for a safety profile evaluation. 2015; 72(2): 310-322

58. Y.K.Tak, S.Pal, P.K.Naoghare, S.Rangasamy, J.M.Song, Scientific Reports, ShapeDependent Skin Penetration of Silver Nanoparticles: Does It Really Matter? 2015; 5: 16908

59. M.A.ALIN, T.COMAN, M.R.CALIN, Romanian Reports in Physics, THE EFFECT OF LOW LEVEL LASER THERAPY ON SURGICAL WOUND HEALING. 2010; 62(3): 617-627

60. R.V.Gonçalves, N.T.A.Souza, P.H.Silva, F.S.Barbosa, C.A.Neves, Fisoter Mov, Influência do laser de arseneto de gálio-alumínio em feridas cutâneas de ratos. 2010; 23: $381-388$

61. M.P.Alfaro, D.L.Deskins, M.Wallus, J.DasGupta, J.M.Davidson, L.B.Nanney, M.A.Guney, M. Gannon, P.P.Young, Lab invest, A physiological role for connective tissue growth factor in early wound healing. 2013; 93(1): 81-95

62. J.Andrae, R.Gallini, C.Betsholtz, Genes Dev, Role of platelet-derived growth factors in physiology and medicine. 2008; 22(10): 1276-1312.

63. S.Guo, L.A.Dipietro, J Dent Res, Factors affecting wound healing. 2010; 89(3): 219229. 
64. M.Pakyari, A.Farrokhi, M.K.Maharlooei, A.Ghahary, Adv Wound Care (New Rochelle), Critical Role of Transforming Growth Factor Beta in Different Phases of Wound Healing. 2013; 2(5): 215-224

65. P.Bao, A.Kodra, M.Tomic-Canic, M.S.Golinko, H.P.Ehrlich, H.Brem, The Role of Vascular Endothelial Growth Factor in Wound Healing, J Surg Res. 2009; 153(2): 347358

66. R.J.Bodnar, Adv Wound Care (New Rochelle), Epidermal Growth Factor and Epidermal Growth Factor Receptor: The Yin and Yang in the Treatment of Cutaneous Wounds and Cancer. 2013; 2(1): 24-29

67. C.Cheng, J.Fan, M.Fedesco, S.Guan, Y.Li, B.Bandyopadhyay, A.M.Bright, D.Yerushalmi, M.Liang, M.Chen, Y.Han, D.T.Woodley, W.Li, MOLECULAR AND CELLULAR BIOLOGY, Transforming Growth Factor (TGF)-Stimulated Secretion of HSP90: Using the Receptor LRP-1/CD91 To Promote Human Skin Cell Migration against a TGF-Rich Environment during Wound Healing. 2008; 28(10) 3344-3358

68. Y.Peng, S.Wu, Q.Tang1, S.Li, C.Peng, JBC, KGF-1 accelerates wound contraction through TGF- $\beta 1 /$ Smads signaling pathway in a double paracrine manner. $2019 ; 294$ : 8361-8370

69. S.Akita, K.Akino, A.Hirano, Adv Wound Care (New Rochelle), Basic Fibroblast Growth Factor in Scarless Wound Healing. 2013; 2(2): 44-49

70. T.N. Mellin, D.E.Cashen, J.J.Ronan, B.S.Murphy, J.DiSalvo, K.A.Thomas, Invest Dermatol, Acidic Fibroblast Growth Factor Accelerates Dermal Wound Healing in Diabetic Mice. 1995; 104(5): 850-855

71. M.A.Gulcelik, S.Dinc, M.Dinc, E.Yenidogan, H.Ustun, N.Renda, H.Alagol, Surg Today, Local Granulocyte-Macrophage Colony-Stimulating Factor Improves Incisional Wound Healing in Adriamycin-Treated Rats. 2006; 36: 47-51

72. B.Naik, P.Karunakar, M.Jayadev, V.R.Marshal, J Conserv Dent, Role of Platelet rich fibrin in wound healing: A critical review. 2013; 16(4): 284-293

73. R.A.N.Achar, T.C.Silva, E.Achar, R.B.Martines, J.L.M.Machado, Acta Cir. Bras, Use of insulin-like growth factor in the healing of open wounds in diabetic and non-diabetic rats. 2014; 29(2): 125-131

74. Y.Kunugiza, N.Tomita, Y.Taniyama, T.Tomita, M.K.Osako, K.Tamai, T.Tanabe, Y.Kaneda, H.Yoshikawa, R.Morishita, Gene Therapy, Acceleration of wound healing by combined gene transfer of hepatocyte growth factor and prostacyclin synthase with Shima Jet. 2006; 13: 1143-1152

75. A.E.Boniakowski, A.S.Kimball, B.N.Jacobs, S.L.Kunkel, K.A.Gallagher, J Immunol, Macrophage-Mediated Inflammation in Normal and Diabetic Wound Healing. 2017; 199(1): 17-24

76. R.E.Mirza, M.M.Fang, W.J.Ennis, T.J.Koh, DIABETES, Blocking Interleukin-1b Induces a Healing-Associated Wound Macrophage Phenotype and Improves Healing in Type 2 Diabetes. 2013; 62: 2579-2587

77. M.Kapoo, S.Liu, K.Huh, S.Parapuram, L.Kennedy, A.Leask, Fibrogenesis \& Tissue Repair, Connective tissue growth factor promoter activity in normal and wounded skin. 2008; 1(3)

78. D.Chicharro-Alcántara, M.Rubio-Zaragoza, E.Damiá-Giménez, J.M.Carrillo-Poveda, B.Cuervo-Serrato, P.Peláez-Gorrea, J.J.Sopena-Juncosa, J. Funct. Biomater, Platelet Rich Plasma: New Insights for Cutaneous Wound Healing Management. 2018; 9(10)

79. S.A.Hashemi, S.A.Madani, S.Abediankenar, BioMed Research International, The Review on Properties of Aloe Vera in Healing of Cutaneous Wounds. 2015: 714216 
80. A.Oryan, A.Mohammadalipou, A.Moshiri, M.Tabandeh, R.Mohammad, Annals of Plastic Surgery, Topical Application of Aloe vera Accelerated Wound Healing, Modeling, and Remodeling. 2016; 77(1): 37-46

81. G.Scapagnini, S.Davinelli, L.D.Renzo, A.D.Lorenzo, H.H.Olarte, G.Micali, A.F.Cicero, S.Gonzalez, Nutrients, Cocoa Bioactive Compounds: Significance and Potential for the Maintenance of Skin Health. 2014; 6: 3202-3213

82. M.Działo, J.Mierziak, U.Korzun, M.Preisner, J.Szopa, A.Kulma, Int. J. Mol. Sci, The Potential of Plant Phenolics in Prevention and Therapy of Skin Disorders. 2016; 17: 160

83. X.Sua, X.Liu, S.Wang, B.Li, T.Pan, D.Liu, F.Wang, Y.Diao, K.Li, Burns, Woundhealing promoting effect of total tannins from Entada phaseoloides (L.) Merr. in rats. 2017; 43(4): 830-838

84. J.Majtan, M.Jesenak, Molecules, $\beta$-Glucans: Multi-Functional Modulator of Wound Healing. 2018; 23: 806

85. D.Akbik, M.Ghadiri, Life Sciences, W.Chrzanowski, R.Rohanizadeh, Curcumin as a wound healing agent. 2014; 116(1): 1-7

86. S.Martinotti, E.Ranzato, Burns \& Trauma, Propolis: a new frontier for wound healing,. 2015; 3(9)

87. S.Martinotti, E.Ranzato, J. Funct. Biomater. Honey, Wound Repair and Regenerative Medicine. 2018; 9(2): 34

88. R.Hobson, IWJ, Vitamin E and wound healing: an evidence-based review. 2016; 13(3): 331-335

89. M.A.Keen, I.Hassan, Indian dermatol Online J, Vitamin E in dermatology. 2016; 7(4): 311-315

90. A.Surjushe, R.Vasani, D.G.Saple, Indian dermatol Online J, Aloe vera: A short review. 2008; 53(4): 163-166

91. H.A.Wallace, B.M.Basehore, P.M.Zito, Treasure Island (FL): StatPearls Publishing, Wound Healing Phases. 2019

92. J.F.Almine, S.G.Wise, A.S.Weiss, Birth Defects Res C Embryo Today, Elastin signaling in wound repair. 2012; 96(3):248-257

93. D.Son, A.Harijan, J Korean Med Sci, Overview of Surgical Scar Prevention and Management. 2014; 29: 751-757

94. K.W.Finnson, S.Mclean G.M.D.Guglielmo, A.Philip, Adv Wound Care (New Rochelle), Dynamics of Transforming Growth Factor Beta Signaling in Wound Healing and Scarring. 2013; 2(5): 195-214

95. J.M.Reinke, H.Sorg, Eur Surg Res, Wound repair and regeneration. 2012; 49(1): 35-43

96. B.J.Larson, M.T.Longaker, H.P.Lorenz, Plast Reconstr Surg, Scarless fetal wound healing: a basic science review. 2010; 126(4): 1172-1180

97. L.Guo, W.Yuan, Z.Lua, C.M.Li, , Colloids and Surfaces A: Physicochemical and Engineering Aspects, Polymer/nanosilver composite coatings for antibacterial applications. 2013; 439(2): 69-83

98. C.Damm, H.Munstedt, A.Rosch, Materials Chemistry and Physics, The antimicrobial efficacy of polyamide 6/silver-nano- and microcomposites. 2008; 108(1): 61-66

99. N.Barrera, L.Guerrero, A.Debut, P.Santa-Cruz, Plos one, Printable nanocomposites of polymers and silver nanoparticles for antibacterial devices produced by DoD technology. 2018; 13(7): e0200918

100. C.Sun ,Y.Li, Z.Li, Q.Su, Y.Wang, X.Liu, Journal of Nanomaterials, Durable and Washable Antibacterial Copper Nanoparticles Bridged by Surface Grafting Polymer Brushes on Cotton and Polymeric Materials. 2018; Article ID 6546193 
101. H.Palza, R.Quijada, K.Delgado, Journal of Bioactive and Compatible Polymers, Antimicrobial polymer composites with copper micro- and nanoparticles: Effect of particle size and polymer matrix. 2015; 30(4)

102. A.F.Jaramillo, S.A.Riquelme, G.Sánchez-Sanhueza, C.Medina, F.Solís-Pomar, D.Rojas, C.Montalba, M.F.Melendrez \& E.Pérez-Tijerina, Nanoscale Research Letters, Comparative Study of the Antimicrobial Effect of Nanocomposites and Composite Based on Poly(butylene adipate-co-terephthalate) Using $\mathrm{Cu}$ and $\mathrm{Cu} / \mathrm{Cu} 2 \mathrm{O}$ Nanoparticles and CuSO4. 2019; 14(158)

103. C.Wang, Q.Cui, X.Wang, L.Li, ACS Appl. Mater. Interfaces, Preparation of Hybrid Gold/Polymer Nanocomposites and Their Application in a Controlled Antibacterial Assay. 2016; 8(42): 29101-29109

104. C.Ryan, E.Alcock, F.Buttimer, M.Schmidt, D.Clarke, M.Pemble, Journal Science and Technology of Advanced Materials, Synthesis and characterisation of cross-linked chitosan composites functionalised with silver and gold nanoparticles for antimicrobial applications. 2017; 18: 528-540

105. H.Liu, C.Wang, C.Li, Y.Qin, Z.Wang, F.Yang, Z.Li, J.Wang, RSC Adv, A functional chitosan-based hydrogel as a wound dressing and drug delivery system in the treatment of wound healing. 2018; 8: 7533-7549

106. M.Bhattarai, J.Gunn, M.Q.Zhang, Adv. Drug delivery Rev, Chitosan-based hydrogels for controlled, localized drug delivery. 2010; 62: 83-99

107. R.C.Goy, D.D.Britto, O.B.G.Assis, Polímeros, A review of the antimicrobial activity of chitosan. 2009; 19(3)

108. Y.Okamoto, R.Yano, K.Miyatake, I.Tomohiro, Y.Shigemasa, S.Minami, CARBOHYDRATE POLYMERS, Effects of chitin and chitosan on blood coagulation. 2003; 53(3): 337-342

109. L.E.Dickinson, S.Gerecht, Front. Physiol, Engineered Biopolymeric Scaffolds for Chronic Wound Healing. 2016; 7: 341

$110 . \quad$ K.Y.Lee, D.J.Mooney, Prog Polym Sci, Alginate: properties and biomedical applications. 2012; 37(1): 106-126

111. A.Kaczmarek-Pawelska, Intchopen, Alginate-Based Hydrogels in Regenerative Medicine, Alginates. 2019: DOI: 10.5772/intechopen.88258

112. B.A.Aderibigbe, B.Buyana, Pharmaceutics, Alginate in Wound Dressings. 2018; 10(42): doi: 10.3390

113. C.B.Highley, G.D.Prestwich, J.A.Burdick, Current Opinion in Biotechnology, Recent advances in hyaluronic acid hydrogels for biomedical applications. 2016; 40: $35-40$

114. X.Xu, A.K.Jha, D.A.Harrington, M.C.Farach-Carson, X.Jia, Soft Matter, Hyaluronic Acid-Based Hydrogels: from a Natural Polysaccharide to Complex Networks. 2012; 8(12): 3280-3294

115. M.Litwiniuk, A.Krejner, T.Grzela, Index: Wounds, Hyaluronic Acid in Inflammation and Tissue Regeneration. 2016; 28(3): 78-88

116. S.Chattopadhyay, R.T.Raines, Biopolymers, Collagen-Based Biomaterials for Wound Healing. 2014; 101(8): 821-833

117. J.Lei, P.Chen, Y.Li, X.Wang, S.Tang, Int J Clin Exp Med, Collagen hydrogel dressing for wound healing and angiogenesis in diabetic rat models. 2017; 10(12): 16319-16327

118. D.Brett, Wounds, A Review of Collagen and Collagen-based Wound Dressings. 2008; 20(12): 347-356

119. S.D.Dutta, D.K. Patel, K.Lim, Journal of Biological Engineering, Functional cellulose-based hydrogels as extracellular matrices for tissue engineering. 2019; 13(55) 
120. E.Pinho, G.Soares, Journal of Materials Chemistry B, Functionalization of cotton cellulose for improved wound healing. 2018; (6)13: 1887-1898

121. S.KISELIOVIENE, O.BANIUKAITIENE, V.HARKAVENKO, N.A.BABENKO, J.LIESIENE, Department of Polymer Chemistry and Technology, Kaunas University of Technology, CELLULOSE HYDROGEL SHEETS FOR WOUND DRESSINGS. 2015

122. S.Dhivya, V.V.Padma, E.SanthinI. Biomedicine (Taipei.), Wound dressings A review. 2015; 5(4): 22

123. B.Manna, C.A.Morrison, Treasure Island (FL): StatPearls Publishing, Wound Debridement. 2019

124. M.F.Akhtar, M.Hanif, N.M.Ranjha, Saudi Pharm J, Methods of synthesis of hydrogels ... A review. 2016; 24(5): 554-559

125. S.Chen, R.Fu, S.Liao, S.Liu, S.Lin, Y.Wang, Cell Transplantation, A PEGBased Hydrogel for Effective Wound Care Management. 2018; 27(2): 275-284

126. R.Stone II, J.T.Wall, S.Natesan and R.J.Christy, Int. J. Mol. Sci PEG-Plasma Hydrogels Increase Epithelialization Using a Human Ex Vivo Skin Model . 2018; 19: 3156

127. E.A.Kamoun, E.S.Kenawy, X.Chen, Journal of Advanced Research, A review on polymeric hydrogel membranes for wound dressing applications: PVA-based hydrogel dressings. 2017; 8(3): 217-233

128. I.Syed, S.Garg. P.Sarkar, Woodhead Publishing Series in Biomaterials, 5 Entrapment of essential oils in hydrogels for biomedical applications, Polymeric Gels, Characterization, Properties and Biomedical Applications. 2018: 125-141

129. E.Rudnik, Compostable Polymer Materials (Second Edition), Chapter 3 Properties and applications. 2019: 49-98

130. N.Roy, N.Saha, PVP-BASED HYDROGELS: SYNTHESIS, PROPERTIES AND APPLICATIONS, Hydrogels: Synthesis, Characterization and Applications. 2012: 227-252

131. N.Roy, N.Saha, T. Kitano, P.Saha, Journal of Soft Materials, Development and Characterization of Novel Medicated Hydrogels for Wound Dressing. 2010; 8(2): 130148

132. S.Zhang, H.Li, M.Yuan, M.Yuan, H.Chen, Int. J. Mol. Sci, Poly(Lactic Acid) Blends with Poly(Trimethylene Carbonate) as Biodegradable Medical Adhesive Material. 2017, 18(10), 2041; https://doi.org/10.3390/ijms 18102041

133. M.Uzun, Journal of Textile Engineering \& Fashion Technology, A Review of Wound Management Materials. 2018; 4(1)

134. A.K.Pandey, A.K.Dwivedi, International Journal of Research in Pharmaceutical Sciences, Recent advancement in wound healing dressing material. 2019; 10(3)

135. S.Kang, J.Bae, S.Park, W.Kim, M.Park, Y.Jin, K.Jang, J.Park, Biotechnology Letters, Combination therapy with BMP-2 and BMSCs enhances bone healing efficacy of PCL scaffold fabricated using the 3D plotting system in a large segmental defect model. 2012; 34(7): 1375-1384

136. E.Malikmammadov, T.E.Tanir, A.Kiziltay, V.Hasirci, N.Hasirci, Journal of Biomaterials science, polymer edition, PCL and PCL-based materials in biomedical applications. 2018; 29(7-9): 863-893

137. J.Joseph, R.M.Patel, A.Wenham, J.R.Smith, The International Journal of Surface Engineering and Coatings, Biomedical applications of polyurethane materials and coatings. 2018; 96(3): 121-129

138. D.E.Heath, S.L.Cooper, Biomaterials Science (Third Edition), A Polyurethanes. 2013: 79-82 
139. S.Hukla, INTERNATIONAL JOURNAL OF PHARMACEUTICAL SCIENCES AND RESEARCH FREEZE DRYING PROCESS: A REVIEW. 2011; 3: 3061-3068

140. S.L.Milind A.P.Santosh, J.T.Zaki, I.D.John, International Journal of Pharmaceutical \& Biological Archives, Polymer Based Wafer Technology: A Review. 2013; 4(6): 1060-107

141. A.T.Pauli, R.WillGrimes, A.Cookman, J.Beiswenger, Advances in Asphalt Materials, 4 - Characterization of asphalt materials by scanning probe microscopy. 2015: 97-132

142. M.J.Jenkins, K.L.Harrison, M.M.C.G.Silva, M.J.Whitaker, K.M.Shakesheff, S.M.Howdle, European polymer J, Characterisation of microcellular foams produced from semi-crystalline PCL using supercritical carbon dioxide. 2006; 42: 3145-3151

143. M.Karimi, M.Heuchel, T.Weigel, M.Schossig, Formation and size distribution of pores in poly( $\varepsilon$-caprolactone) foams prepared by pressure quenching using supercritical CO2, Journal of supercritical fluids, 61 2012, 175-190

144. S.Agarwal, J.H.Wendorff, A.Greiner, Polymer, Use of electrospinning technique for biomedical applications. 2008; 49(26): 5603-5621

145. http://polybiolab.ippt.pan.pl/18-few-words-about/17-electrospinning

146. X.Shi, W.Zhou, D.Ma, Q.Ma, D.Bridges, Y.Ma, A.Hu, Journal of Nanomaterials, Electrospinning of Nanofibers and Their Applications for Energy Devices. 2015: Article ID 140716

147. T.Huber, D.Clucas, M.Vilmay, B.Pupkes, J.Stuart, S.Dimartino, C.Fee, Journal of manufacturing and materials processing, 3D Printing Cellulose Hydrogels Using LASER Induced Thermal Gelation. 2018; 2(42)

148. Z.Chen, D.Zhao, B.Liu, G.Nian, X.Li, J.Yin, S.Qu, W.Yang, Advanced functional materials, 3D Printing of Multifunctional Hydrogels. 2019; 29: 1900971

149. K.H.Hussein, K.Park, Y.Lee, J.Woo, B.Kang, K.Choi, K.Kang, H.Woo, Int J Artif Organs, New insights into the pros and cons of cross-linking decellularized bioartificial organs. 2017;40(4):136-141

150. W.Hu, Z.Wang, Y.Xiao, S.Zhanga, J.Wang, Biomaterials Science, Advances in crosslinking strategies of biomedical hydrogels. 2019; 7: 843-855

151. G.Somya, P.Nayyar, B.Akanksha, S.P.Kumar, Egyptian pharmaceutical journal, Interpenetrating polymer network-based drug delivery systems: emerging applications and recent patents. 2015; 14(2): 75-86

152. E.S.Dragan, Chemical engineering journal, Design and applications of interpenetrating polymer network hydrogels.A review. 2014; 243: 572-590

153. X.Hu, L.Feng, A.Xie, W.Wei, S.Wang, J.Zhanga, W.Dong, Journal of Materials Chemistry B, Synthesis and characterization of a novel hydrogel: salecan/polyacrylamide semi-IPN hydrogel with a desirable pore structure. 2014; 23(2): 3646-3658

154. M.Ginting, I.Masmur, S.P.Pasaribu, Hestina, RSC Advances, A simple one-pot fabrication of silver loaded semi-interpenetrating polymer network (IPN) hydrogels with self-healing and bactericidal abilities. 2019; 9(67): 39515-39522

155. Y.Liu, K.Zhang, J.Ma, G.J.Vancso, Mater. Interfaces, Thermoresponsive SemiIPN Hydrogel Microfibers from Continuous Fluidic Processing with High Elasticity and Fast Actuation, ACS Appl. 2017; 9(1): 901-908

156. E.M.Ahmed, Journal of Advanced Research, Hydrogel: Preparation, characterization, and applications: A review. 2015; 6(2): 105-121

157. A.Bhattacharyaa, B.N.Misra, Grafting: a versatile means to modify polymers Techniques, factors and applications, Prog. Polym. Sci. 2004; 29: 767-814 
158. Y.Cai, Q.Wei, F.Huang, Functional Nanofibers and their Applications, 3 Processing of composite functional nanofibers. 2012: 38-54

159. P.McClellan, W.J.Landis, BioResearch Open Access, Recent Applications of Coaxial and Emulsion Electrospinning Methods in the Field of Tissue Engineering. 2016; 5.1

160. S.Shen, Y.Wu, Y.Liu, D.Wu, International Journal of Nanomedicine, High drug-loading nanomedicines: progress, current status, and prospects. 2017 ; 12: 40854109

161. S.Vrignaud, J.Benoit, P.Saulnier, Biomaterials, Strategies for the nanoencapsulation of hydrophilic molecules in polymer-based nanoparticles. 2011; 32(33): 8593-8604

162. K.W.Bayles, Nat Rev Microbiol, Bacterial Programmed Cell Death: Making Sense of a Paradox. 2014; 12(1): 63-69

163. M.Volmer-Thole, R.Lobmann. Int J Mol Sci, Neuropathy and Diabetic Foot Syndrome. 2016; 17(6): 917

164. S.A.Eming, T.Krieg, J.M.Davidson, J Invest Dermatol, Inflammation in wound repair: molecular and cellular mechanisms. 2007; 127(3): 514-525

165. R.E.Mirza, M.M.Fang, M.L.Novak, N.Urao, A.Sui, W.J.Ennis, J Pathol, Macrophage PPAR $\gamma$ and impaired wound healing in type 2 diabetes. 2015; 236(4): 433444

166. C.D.Mills, L.L.Lenz, R.A.Harris, Cancer Res, A breakthrough: macrophagedirected cancer Immunotherapy. 2016; 76: 513-516

167. B.Deng, M.Wehling-Henricks, S.A.Villalta, Y.Wang, J.G.Tidball, J Immunol, IL-10 triggers changes in macrophage phenotype that promote muscle growth and regeneration. 2012; 189(7): 3669-3680

168. M.Hesketh, K.B.Sahin, Z.E.West, R.Z.Murray, Int J Mol Sci, Macrophage Phenotypes Regulate Scar Formation and Chronic Wound Healing. 2017; 18(7)

169. P.M.Elias, J Dermatol, The stratum corneum revisited. 1996; 23: 756-68

170. D.Jenerowicz, W.Silny, A.Danczak-Pazdrowska, A.Polanska, A.OsmolaMankowska, B.Olek-Hrab, Ann Agric Environ Med Environmental factors and allergic diseases. 2012; 19: 475-481

171. J.Rogers, C.Harding, A.Mayo, J.Banks, A.Rawlings, Arch Dermatol Res Stratum corneum lipids: the effect of ageing and the seasons. 1996; 288: 765-770

172. M.Ngaage, M.Agius. Psychiatria Danubina, The Psychology Of Scars: A MiniReview. 2018; 30(7): 633-638

173. J.E.Ireton, J.G.Unger, MD, R.J.Rohrich, Plast reconstr Surg Glob Open, The Role of Wound Healing and Its Everyday Application in Plastic Surgery: A Practical Perspective and Systematic Review. 2013; 1(1): e10-e19

174. L.Muthusubramaniam, T.Zaitseva, M.Paukshto, G.Martin, T.Desai, Tissue Engineering: Part A, Effect of Collagen Nanotopography on Keloid Fibroblast Proliferation and Matrix Synthesis: Implications for Dermal Wound Healing. 2014; 20 (19-20) 
This is a peer-reviewed, accepted author manuscript of the following research article: Man, E., \& Hoskins, C. (Accepted/In press). Towards advanced wound regeneration. European Journal of Pharmaceutical Sciences.

\section{Figures}

Figure 1. Diagram detailing the hierarchal structure of the epidermis

Figure 2. Diagram detailing the structural hierarchy of the dermal epidermal junction

Figure 3. Diagram detailing the mechanism of bacteriophage therapy

Figure 4. Diagram detailing the mechanisms of nano-metal induced ROS 


\section{Figure 1.}

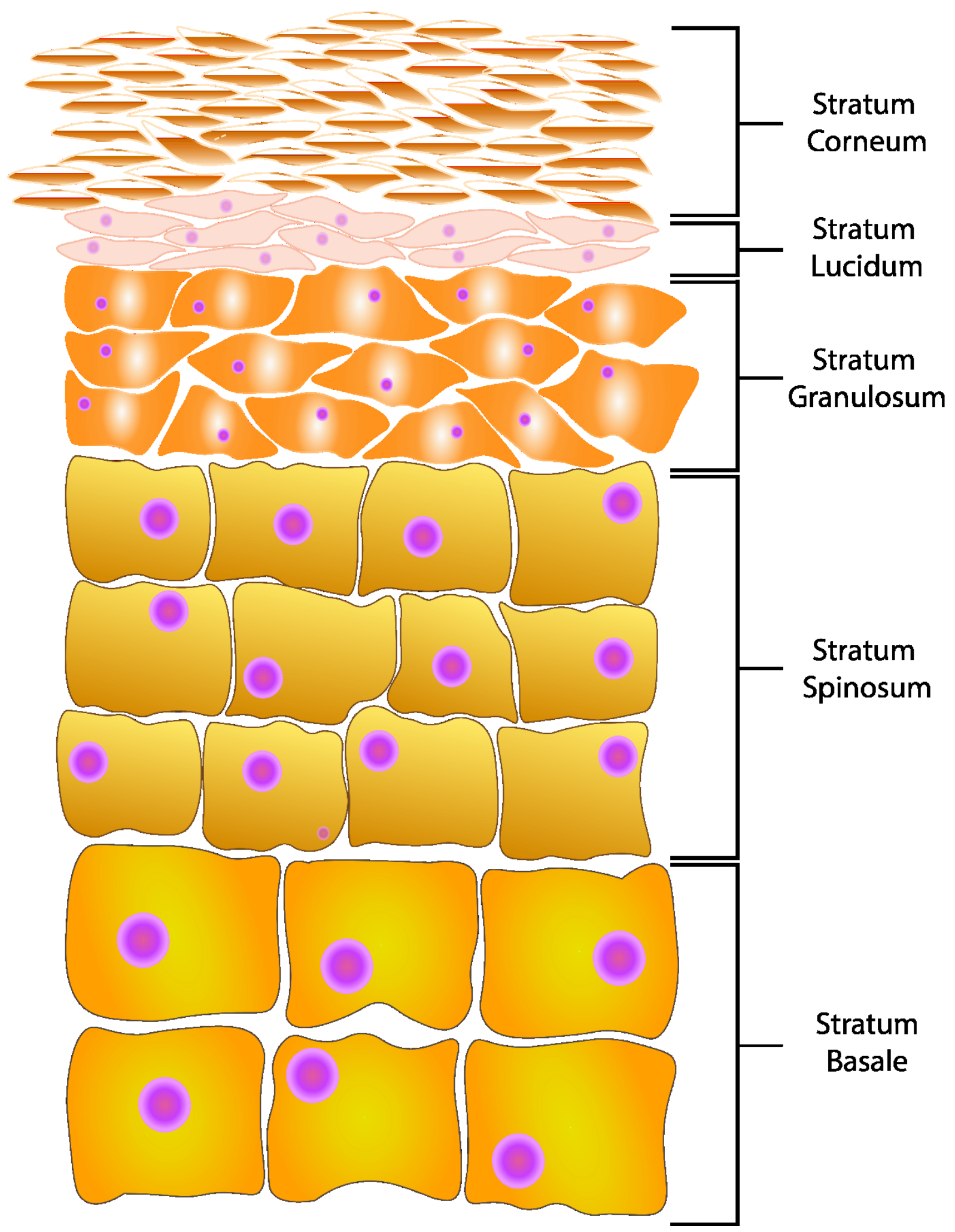


This is a peer-reviewed, accepted author manuscript of the following research article: Man, E., \& Hoskins, C. (Accepted/In press). Towards advanced wound regeneration. European Journal of Pharmaceutical Sciences.

\section{Figure 2}

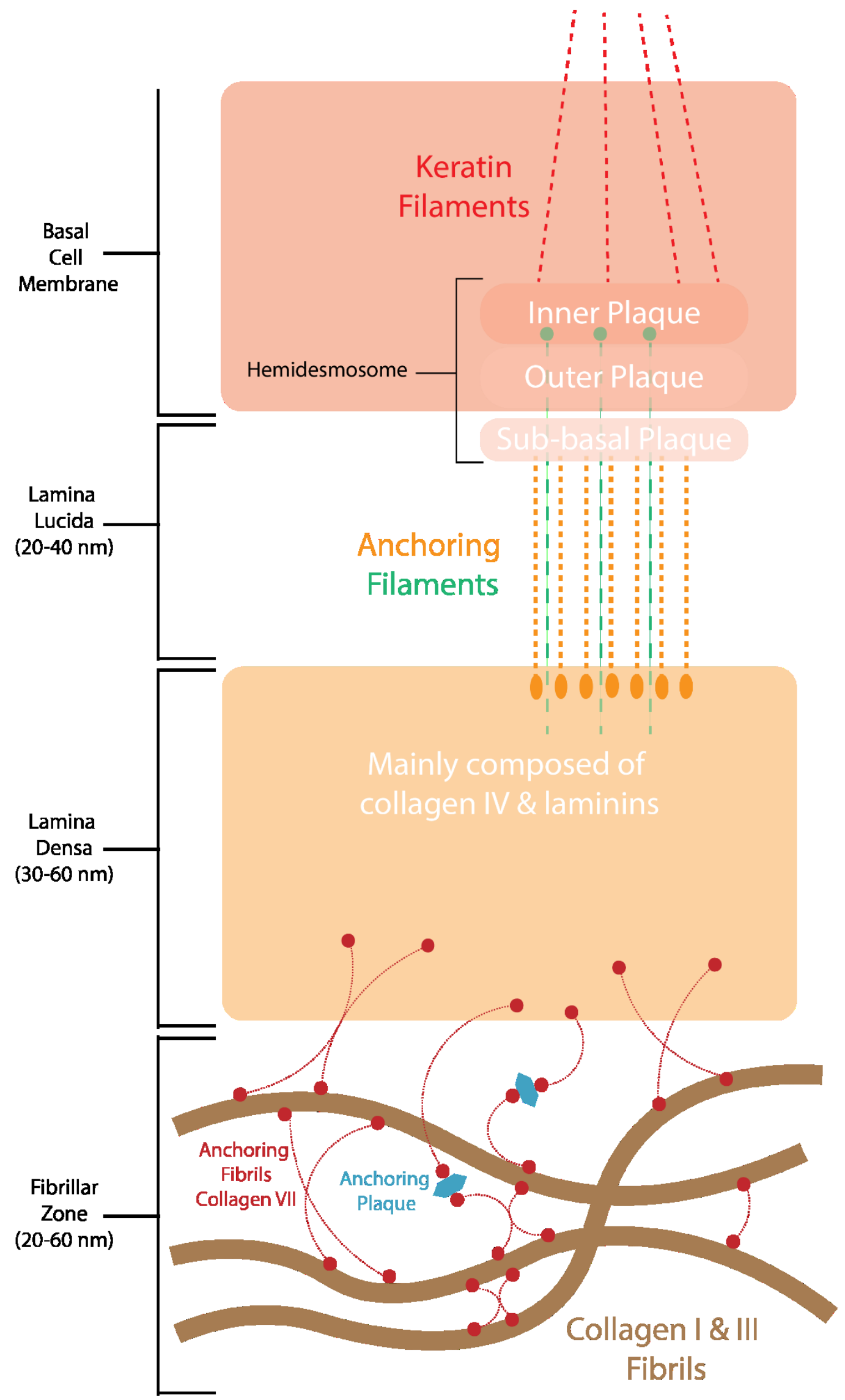


This is a peer-reviewed, accepted author manuscript of the following research article: Man, E., \& Hoskins, C. (Accepted/In press). Towards advanced wound regeneration. European Journal of Pharmaceutical Sciences.

\section{Figure 3.}

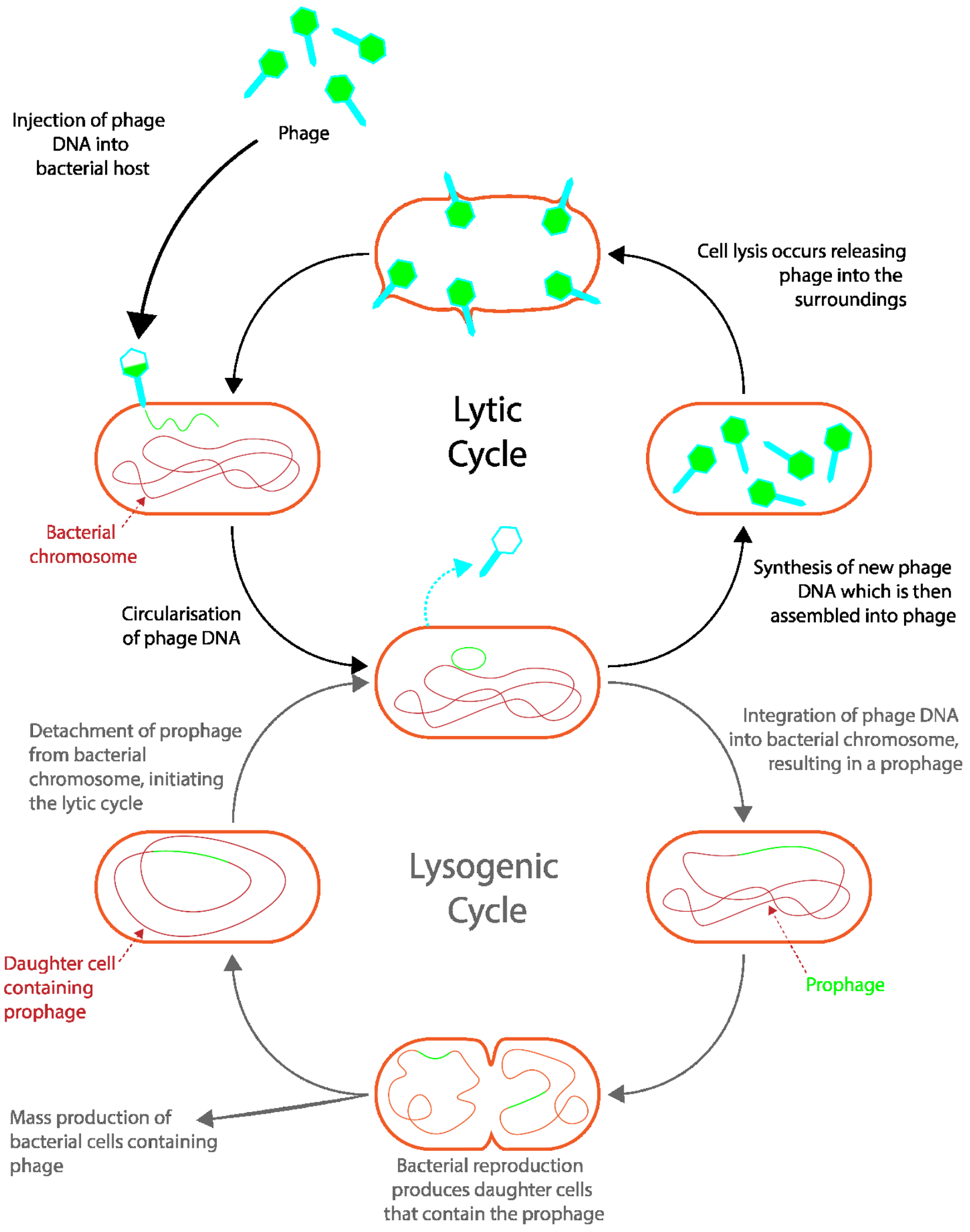


This is a peer-reviewed, accepted author manuscript of the following research article: Man, E., \& Hoskins, C. (Accepted/In press). Towards advanced wound regeneration. European Journal of Pharmaceutical Sciences.

\section{Figure 4.}

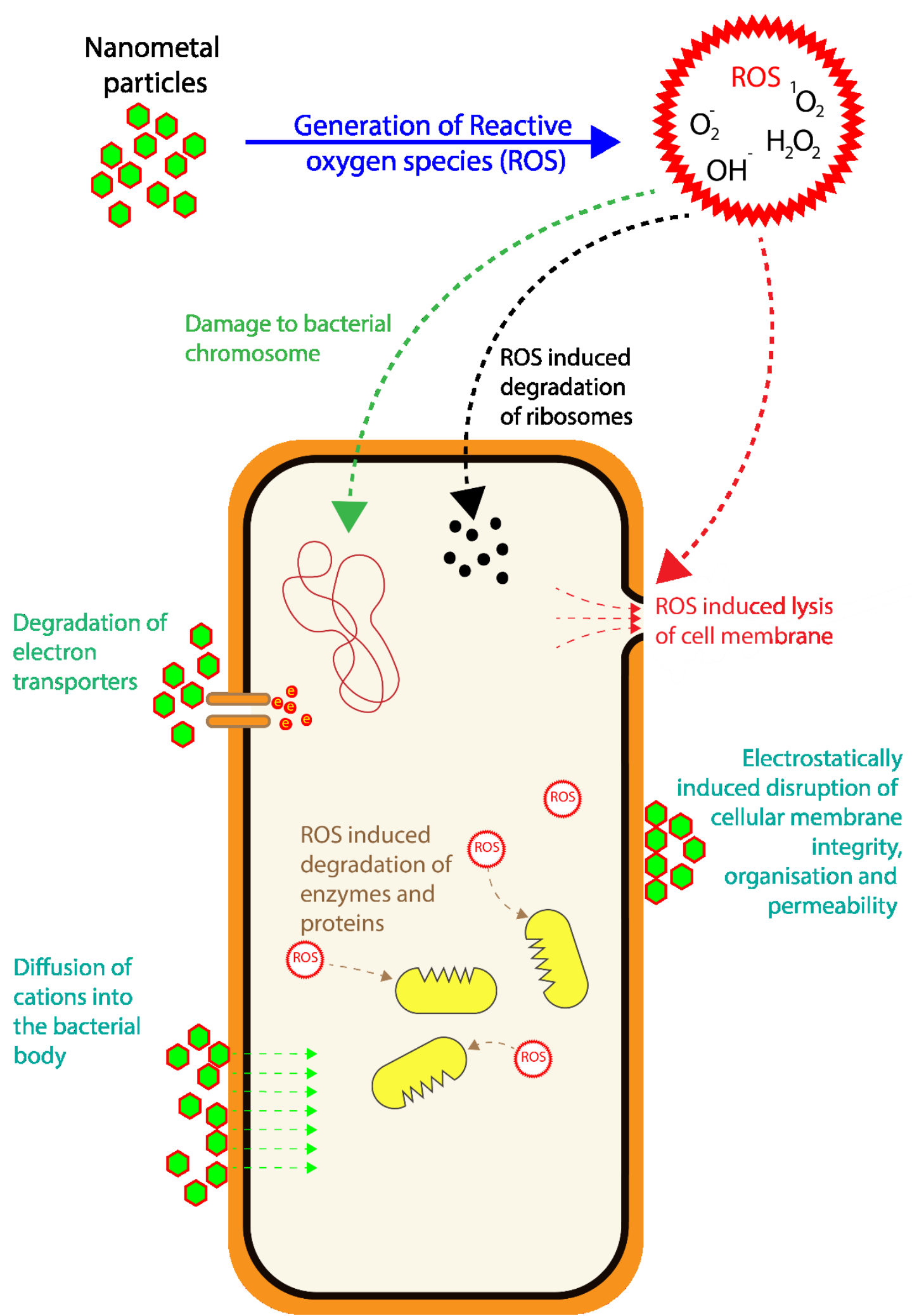


This is a peer-reviewed, accepted author manuscript of the following research article: Man, E., \& Hoskins, C. (Accepted/In press). Towards advanced wound regeneration. European Journal of Pharmaceutical Sciences.

\section{Tables}

Table 1. List of growth factors and their specific physiological functions.

\begin{tabular}{|c|c|c|c|}
\hline Growth factor & Topical effects & Extra information & Reference \\
\hline $\begin{array}{l}\text { Platelet derived } \\
\text { growth factor } \\
\text { alpha } \\
\text { (PDGF- } \alpha \text { ) }\end{array}$ & $\begin{array}{l}\text {-For the development of cardiac neural } \\
\text { crests, skin, etc } \\
\text {-Mesodermal cell migration in xenopus } \\
\text { gastrulation }\end{array}$ & \multirow{2}{*}{$\begin{array}{l}\text {-Limited evidence for physiological use in } \\
\text { adults. } \\
\text {-Drives pathological mesenchymal responses } \\
\text { associated with vascular diseases } \\
\text {-Causative role of PDGF signalling in some } \\
\text { cancers } \\
\text {-Promotion of the inflammatory phase in wound } \\
\text { regeneration } \\
\text {-Promotion of fibroblast migration in the } \\
\text { proliferative phase of wound regeneration } \\
\text {-Stimulates production of fibronectin and } \\
\text { collagens for the maturation phase in wound } \\
\text { regeneration }\end{array}$} & \multirow[t]{2}{*}[62-64]{} \\
\hline $\begin{array}{l}\text { Platelet derived } \\
\text { growth factor } \\
\text { beta } \\
\text { (PDGF- } \beta)\end{array}$ & $\begin{array}{l}\text {-For blood vessel formation and early } \\
\text { haematopoiesis }\end{array}$ & & \\
\hline $\begin{array}{l}\text { Vascular } \\
\text { endothelial } \\
\text { growth factor } \\
\text { (VEGF) }\end{array}$ & $\begin{array}{l}\text {-Stimulation of angiogenesis via } \\
\text { endothelial cell migration and } \\
\text { proliferation } \\
\text {-Induction of procoagulants in } \\
\text { endothelial cells } \\
\text {-Delays senescence } \\
\text {-Prevents apoptosis } \\
\text {-Restores proliferative potential for } \\
\text { endothelial cells }\end{array}$ & $\begin{array}{l}\text {-Endothelial migration occurs via vasodilation } \\
\text { and chemotaxis } \\
\text {-Induction of surface matrix endothelial cells to } \\
\text { invade the matrix below } \\
\text {-The levels of VEGF expression can be used as } \\
\text { to identify the regeneration progress }\end{array}$ & [65] \\
\hline $\begin{array}{l}\text { Epidermal } \\
\text { growth factor } \\
\text { (EGF) }\end{array}$ & $\begin{array}{l}\text {-Stimulation of cutaneous regeneration } \\
\text { via epithelial cell motility } \\
\text {-Key stimulator for wound closure and } \\
\text { the migration of fibroblasts } \\
\text {-Mediates keratinocyte } \\
\text { de-differentiation into an epithelial } \\
\text { phenotype } \\
\text {-Required for dermal maturation and } \\
\text { re-epithelization }\end{array}$ & $\begin{array}{l}\text {-EGF initiates the processes of migration, } \\
\text { mitogenesis and cytoprotection which is needed } \\
\text { for tissue regeneration } \\
\text {-Topical application of human recombinant } \\
\text { EGF results in enhanced wound healing and re- } \\
\text { epithelization } \\
\text {-EGF receptors overexpressed in solid tumours } \\
\text {-Promotion of the inflammatory phase in wound } \\
\text { regeneration }\end{array}$ & {$[63,66]$} \\
\hline $\begin{array}{l}\text { Transforming } \\
\text { growth factor } \\
\text { alpha } \\
(\text { TGF- } \alpha)\end{array}$ & $\begin{array}{l}\text {-Stimulation and enhancement of } \\
\text { keratinocyte migration and proliferation } \\
\text {-stimulates the migration of dermal } \\
\text { fibroblasts } \\
\text {-Initiates translocation of hsp } 90 \alpha \text { which } \\
\text { is needed for the migration of cutaneous } \\
\text { cells }\end{array}$ & $\begin{array}{l}\text {-Functions primarily as a paracrine and } \\
\text { autocrine growth factor } \\
\text {-Main driver of human keratinocyte migration }\end{array}$ & {$[63,67]$} \\
\hline $\begin{array}{l}\text { Transforming } \\
\text { growth factor } \\
\text { beta } \\
(\text { TGF- } \beta)\end{array}$ & $\begin{array}{l}\text {-Influences the transformation of } \\
\text { monocytes into macrophages upon their } \\
\text { transition into the site of injury } \\
\text {-Stimulates the formation of granular } \\
\text { tissue } \\
\text {-Promotion of angiogenesis } \\
\text {-TGF- } \beta 1 \text { promotes fibroblast migration } \\
\text { in the proliferative phase of wound } \\
\text { regeneration } \\
\text {-TGF- } \beta 1 \text { stimulates production of } \\
\text { fibronectin and collagens for the } \\
\text { maturation phase in wound regeneration }\end{array}$ & $\begin{array}{l}\text {-Involved in different stages of wound healing } \\
\text {-Excess will lead to over-healing, } \\
\text {-Excess deposition of elastin and collagen can } \\
\text { result in keloids and hypertrophic scars } \\
\text {-Promotion of the inflammatory phase in wound } \\
\text { regeneration } \\
\text {-Facilitation of blood to the site of injury } \\
\text {-TGF- } \beta 1 \text { exerts immunosuppressive effects, } \\
\text { resulting in the potential build-up of tumour } \\
\text { cells. } \\
\text {-TGF- } \beta 2 \text { needed to express and organise } \\
\text { collagen and during scar formation }\end{array}$ & {$[63,64,68]$} \\
\hline
\end{tabular}


This is a peer-reviewed, accepted author manuscript of the following research article: Man, E., \& Hoskins, C. (Accepted/In press). Towards advanced wound regeneration. European Journal of Pharmaceutical Sciences.

\begin{tabular}{|c|c|c|c|}
\hline & $\begin{array}{l}\text {-TGF- } \beta 1 \text { promotes keratinocyte } \\
\text { migration } \\
- \text { TGF- } \beta 1 \text { promotes differentiation of } \\
\text { fibroblasts into myofibroblasts } \\
- \text { TGF- } \beta 1 \text { promotes contraction of } \\
\text { fibroblasts for wound closure } \\
\text {-TGF- } \beta 2 \text { promotes immune cell and } \\
\text { fibroblast recruitment to the site of injury }\end{array}$ & & \\
\hline $\begin{array}{l}\text { Basic fibroblast } \\
\text { growth factor } \\
\text { (bFGF) }\end{array}$ & $\begin{array}{l}\text {-Stimulates cutaneous fibroblast } \\
\text { proliferation } \\
\text {-Stimulate angiogenesis and the } \\
\text { upregulation of hyaluronic acid in } \\
\text { cutaneous fibroblasts } \\
\text {-Enhances the localisation of leukocytes } \\
\text { to the area of inflammation resulting in } \\
\text { improved cutaneous healing } \\
\text {-Induces tissue remodelling, } \\
\text { neovascularization and wound healing } \\
\text {-Inhibition of terminal differentiation to } \\
\text { myofibroblast }\end{array}$ & $\begin{array}{l}\text {-Widely used in the clinical application of } \\
\text { accelerated ulcer and wound healing } \\
\text {-Normalises tissue texture and colour of } \\
\text { repaired skin relative to the neighbouring } \\
\text { healthy skin } \\
\text {-Helps to reduce scar formation } \\
\text {-Promotion of the inflammatory phase in wound } \\
\text { regeneration } \\
\text {-Usage should be avoided for those with cancer }\end{array}$ & {$[63,69]$} \\
\hline $\begin{array}{l}\text { Acidic } \\
\text { fibroblast } \\
\text { growth factor } \\
(\mathrm{aFGF})\end{array}$ & $\begin{array}{l}\text {-Promotes the mitogenesis of epidermal } \\
\text { keratinocytes, dermal fibroblasts and } \\
\text { vascular endothelial cells. } \\
\text {-Stimulates angiogenesis } \\
\text {-Accelerates the rate of healing }\end{array}$ & $\begin{array}{l}\text {-Promotion of the inflammatory phase in wound } \\
\text { regeneration } \\
\text {-High binding affinity to all known FGF } \\
\text { receptors } \\
\text {-Wound healing enhancement is dose dependent }\end{array}$ & {$[63,70]$} \\
\hline $\begin{array}{l}\text { Keratinocyte } \\
\text { growth factor } \\
\quad(\mathrm{KGF})\end{array}$ & $\begin{array}{l}\text {-KGF-1 Promotes indirect wound } \\
\text { contraction } \\
\text {-Indirect induction of TGF- } \beta 1 \text { expression } \\
\text { via the stimulation of keratinocytes }\end{array}$ & $\begin{array}{l}\text {-Facilitates vascularization and reepithelization } \\
\text {-No effect on fibroblasts when the keratinocytes } \\
\text { were absent } \\
\text {-Is a paracrine growth factor } \\
\text {-Expression increases } 160 x \text { postinjury }\end{array}$ & [68] \\
\hline $\begin{array}{l}\text { Granulocyte } \\
\text { macrophage } \\
\text { colony } \\
\text { stimulating } \\
\text { factor } \\
\text { (GM-CSF) }\end{array}$ & $\begin{array}{l}\text {-Increases the number of keratinocytes } \\
\text { and Langerhans cells in cutaneous tissue } \\
\text {-Induction of enchorial migration and } \\
\text { proliferation } \\
\text {-Antimicrobial effect via the stimulated } \\
\text { increase in monocyte and macrophage } \\
\text { populations } \\
\text {-Increases collagen synthesis via } \\
\text { fibroblast activation }\end{array}$ & $\begin{array}{l}\text {-Local application improves wound healing } \\
\text {-Systemic application of GM-CSF does not } \\
\text { reach a level of concentration that is high } \\
\text { enough to exert a healing effect in the wound } \\
\text { area } \\
\text {-Increases the inflammatory response } \\
\text {-Increases neovascularisation and arteriogenesis } \\
\text {-Reduction in necrosis }\end{array}$ & [71] \\
\hline $\begin{array}{l}\text { Platelet rich } \\
\text { fibrin } \\
\text { (PRF) }\end{array}$ & $\begin{array}{l}\text {-Promotes haemostasis, regeneration of } \\
\text { bone wound healing and sealing. }\end{array}$ & $\begin{array}{l}\text {-Presence of fibrin matrix allows better } \\
\text { directional migration of stem cells, resulting in } \\
\text { improved healing } \\
\text {-Acts as a scaffold for cellular growth }\end{array}$ & [72] \\
\hline $\begin{array}{l}\text { Insulin-like } \\
\text { growth factor } \\
\text { (IGF) }\end{array}$ & $\begin{array}{l}\text {-Stimulates keratinocyte mitogenesis } \\
\text {-Stimulates myofibroblast proliferation } \\
\text { and differentiation } \\
\text {-Promotes collagen synthesis and } \\
\text { angiogenesis }\end{array}$ & $\begin{array}{l}\text {-Topical application results in increased } \\
\text { expressions of myofibroblasts within the } \\
\text { wound, leading to improved scarring results. }\end{array}$ & [73] \\
\hline $\begin{array}{l}\text { Hepatocyte } \\
\text { Growth Factor } \\
(\mathrm{HGF})\end{array}$ & $\begin{array}{l}\text {-Enhances keratinocyte migration, } \\
\text { growth and DNA synthesis, leading to } \\
\text { improved wound healing } \\
\text {-Enhances angiogenesis via the } \\
\text { migration, organisation and proliferation } \\
\text { of vascular endothelial cells } \\
\text {-Stimulates tissue granulation and } \\
\text { vascularization }\end{array}$ & $\begin{array}{l}\text {-HGF expression increases as a result of } \\
\text { wounding }\end{array}$ & [74] \\
\hline
\end{tabular}


This is a peer-reviewed, accepted author manuscript of the following research article: Man, E., \& Hoskins, C. (Accepted/In press). Towards advanced wound regeneration. European Journal of Pharmaceutical Sciences.

\begin{tabular}{|c|l|l|}
\hline $\begin{array}{c}\text { Interleukin-1 } \\
\text { (IL-1) }\end{array}$ & $\begin{array}{l}\text {-Inhibition of IL-1 } \beta \text { downregulates } \\
\text { macrophage M1 which is associated with } \\
\text { proinflammation and upregulates } \\
\text { macrophage M2 which is associated with } \\
\text { wound healing }\end{array}$ & $\begin{array}{l}\text {-Macrophage M2 induces increased levels of } \\
\text { TGF- } \beta \text { and VEGF which are required for the } \\
\text { influx of fibroblasts and angiogenesis } \\
\text { respectively } \\
\text {-IL-1 } \beta \text { follows a positive feedback loop, } \\
\text { inducing itself, leading to sustained } \\
\text { inflammation in chronic wounds }\end{array}$ \\
\hline $\begin{array}{c}\text { Connective } \\
\text { Tissue Growth } \\
\text { Factor } \\
\text { (CTGF) }\end{array}$ & $\begin{array}{l}\text {-Induction of fibroblasts and } \\
\text { myofibroblasts during tissue repair phase }\end{array}$ & $\begin{array}{l}\text {-Marker of fibroblast activation and fibrogenesis } \\
\text {-Can be pathological, contributing to impaired } \\
\text {-Induces matrix deposition } \\
\text { healing and fibrosis, however this is dependent } \\
\text { on the duration, timing and concentration of } \\
\text { CTGF at specific points in the wound repair } \\
\text { process. } \\
\text {-Early administration of CTGF has therapeutic } \\
\text { benefits, however sustained dosage above a } \\
\text { specific threshold can lead to fibrosis } \\
\text {-Modulated by TGF- } \beta\end{array}$ \\
\hline
\end{tabular}


This is a peer-reviewed, accepted author manuscript of the following research article: Man, E., \& Hoskins, C. (Accepted/In press). Towards advanced wound regeneration. European Journal of Pharmaceutical Sciences.

Table 2. List of natural compounds associated with cutaneous repair and their specific physiological functions.

\begin{tabular}{|c|c|c|c|c|}
\hline Substance & Source & Topical effect & Further information & Reference \\
\hline $\begin{array}{c}\text { Aloe } \\
\text { polysaccharides }\end{array}$ & Aloe vera & $\begin{array}{l}\text {-Stimulates keratinocyte migration and } \\
\text { proliferation } \\
\text {-Stimulates fibroblast proliferation, } \\
\text { migration } \\
\text {-Enhances the synthesis of collagen, } \\
\text { wound contraction and fibroplasia } \\
\text {-Induced increased expression of VEGF } \\
\text { and TGF- } \beta 1 \\
\text {-Induces better alignment of collagen } \\
\text { fibres leading to decreased scar tissue } \\
\text { size } \\
\text {-Increased structural organisation of } \\
\text { granular tissue leading to faster } \\
\text { formation of scar tissue }\end{array}$ & $\begin{array}{l}\text {-Ineffective for the treatment of } \\
\text { radiation } \\
\text {-Effective for the treatment of } \\
\text { burns by accelerating re- } \\
\text { epithelization } \\
\text {-Improves keratinocyte viability } \\
\text {-High dose increases fibrocyte } \\
\text { and macrophage count whilst } \\
\text { decreasing total cellularity } \\
\text {-High dose increases the quality } \\
\text { and rate of fibrous tissue } \\
\text { formation and inflammation }\end{array}$ & {$[78-80]$} \\
\hline Polyphenols & $\begin{array}{l}\text { Cocoa, } \\
\text { Tree bark, } \\
\text { Plants }\end{array}$ & $\begin{array}{l}\text {-Enhances dermal blood flow and UV } \\
\text { photoprotection } \\
\text {-Induces xenobiotic response } \\
\text {-Inhibits proinflammatory mediators } \\
\text {-Antibacterial, antiviral, antifungal } \\
\text { activity } \\
\text {-Antioxidant, ROS neutralisation } \\
\text {-Stimulates elastin and collagen } \\
\text { synthesis }\end{array}$ & $\begin{array}{l}\text {-Helps to maintain cutaneous } \\
\text { health } \\
\text {-Strong antioxidant, inhibiting } \\
\text { lipid peroxidation and ROS } \\
\text {-Improves vascular endothelial } \\
\text { immunoregulation } \\
\text {-Suppresses melanin synthesis }\end{array}$ & {$[81-83]$} \\
\hline Theobromine & Cocoa & -Antioxidant activity, absorption of ROS & -Uv photoprotection & {$[80]$} \\
\hline Tannin & $\begin{array}{l}\text { Tree bark, } \\
\text { Plants }\end{array}$ & $\begin{array}{l}\text {-Antibacterial activity via disruption to } \\
\text { cell wall synthesis resulting in the } \\
\text { outflow of bacterial cytoplasm } \\
\text {-Enhances collagen synthesis }\end{array}$ & $\begin{array}{l}\text {-Enhanced proliferation of } \\
\text { fibroblasts }\end{array}$ & [83] \\
\hline$\beta$-Glucans & $\begin{array}{c}\text { Fungi, grain, } \\
\text { yeast }\end{array}$ & $\begin{array}{l}\text {-Acceleration of healing in acute and } \\
\text { chronic wounds via the activation of } \\
\text { cutaneous and immune cells } \\
\text {-Contribute to wound closure } \\
\text {-Stimulates reepithelialisation and } \\
\text { collagen deposition }\end{array}$ & $\begin{array}{l}\text {-Immunomodulatory and anti- } \\
\text { inflammatory effects } \\
\text {-Antimicrobial effects } \\
\text {-Enhancement of tissue } \\
\text { regeneration via stimulated cell } \\
\text { proliferation and migration }\end{array}$ & {$[84]$} \\
\hline Curcumin & Turmeric & $\begin{array}{l}\text {-Stimulates cutaneous regeneration via } \\
\text { the formation of granular tissue, } \\
\text { remodelling of tissue and the deposition } \\
\text { of collagen. } \\
\text {-Improves the fibroblast proliferation } \\
\text { rate and enhances the regeneration of } \\
\text { epithelial cells. } \\
\text {-Increases production of TGF- } \beta\end{array}$ & $\begin{array}{l}\text {-Anti-inflammatory, antioxidant } \\
\text { effects } \\
\text {-Low bioavailability, light } \\
\text { sensitive, poor solubility and is } \\
\text { rapidly metabolised }\end{array}$ & {$[85]$} \\
\hline Propolis & $\begin{array}{l}\text { Honeybee } \\
\text { hive walls }\end{array}$ & $\begin{array}{l}\text {-Antioxidation via the deactivation of } \\
\text { ROS } \\
\text {-Stimulates cell proliferation or } \\
\text { apoptosis, depending on the constituents } \\
\text { of the propolis }\end{array}$ & $\begin{array}{l}\text {-Anti-inflammation for chronic } \\
\text { and acute inflammation } \\
\text {-Antimicrobial effects against } \\
\text { some gram-positive and gram- } \\
\text { negative bacteria } \\
\text {-Contact dermatitis can occur }\end{array}$ & {$[86]$} \\
\hline $\begin{array}{l}\text { Proteins, } \\
\text { vitamins, }\end{array}$ & Honey & $\begin{array}{l}\text {-Inhibits microbial growth via the } \\
\text { production of hydrogen peroxide which } \\
\text { is generated by enzymatic processes and }\end{array}$ & $\begin{array}{l}\text {-Inhibition of anaerobic and } \\
\text { aerobic bacteria } \\
\text {-Inhibition of gram-positive and }\end{array}$ & [87] \\
\hline
\end{tabular}


This is a peer-reviewed, accepted author manuscript of the following research article: Man, E., \& Hoskins, C. (Accepted/In press). Towards advanced wound regeneration. European Journal of Pharmaceutical Sciences.

\begin{tabular}{|c|l|l|l|}
\hline $\begin{array}{c}\text { minerals, phenols, } \\
\text { organic acids }\end{array}$ & $\begin{array}{l}\text { also via lysozyme } \\
\text {-Promotes and represses inflammation } \\
\text { via the stimulation or inhibition of } \\
\text { cytokines } \\
\text {-Modulates the activation and } \\
\text { deactivation of ROS from neutrophils }\end{array}$ & $\begin{array}{l}\text { gram-negative bacteria } \\
\text {-Promotes reepithelization }\end{array}$ \\
\hline Tocopherol & $\begin{array}{l}\text { Vegetables, } \\
\text { nuts, whole } \\
\text { grains }\end{array}$ & $\begin{array}{l}\text { - } \alpha \text {-tocopherol induces fibroblast } \\
\text { stabilisation and activation in-vitro } \\
\text {-Inhibits the UV induced keratinocyte } \\
\text { apoptosis } \\
\text {-Epidermal protection against oxidative } \\
\text { stress } \\
\text {-Antioxidative activity }\end{array}$ & $\begin{array}{l}\text { - Immunosuppressive effects } \\
\text {-Gradually oxidises in air } \\
\text { to a variety of side effects } \\
\text { including nausea, fatigue, } \\
\text { weakness, bruising and bleeding } \\
\text { etc }\end{array}$ \\
\hline
\end{tabular}


This is a peer-reviewed, accepted author manuscript of the following research article: Man, E., \& Hoskins, C. (Accepted/In press). Towards advanced wound regeneration. European Journal of Pharmaceutical Sciences.

Table 3. Detailing the various aspects regarding the use of a specific polymer for wound regeneration.

\begin{tabular}{|c|c|c|c|c|c|}
\hline Polymer & Properties & Advantages & Disadvantages & Application & Reference \\
\hline $\begin{array}{l}\text { Chitosan } \\
\text { (sourced } \\
\text { from chitin) }\end{array}$ & $\begin{array}{l}\text {-Haemostatic } \\
\text {-Antimicrobial } \\
\text {-Biocompatible } \\
\text {-Biodegradable } \\
\text {-Bio-adhesive } \\
\text {-Non-toxic } \\
\text {-Non-antigenic } \\
\text {-Net cationic } \\
\text { charge } \\
\text {-Hydrophilic } \\
\text {-Gelation } \\
\text {-Film forming } \\
\text { capabilities }\end{array}$ & $\begin{array}{l}\text {-Highly abundant } \\
\text {-Easy to source } \\
\text {-Inexpensive } \\
\text {-Hydrophilic nature is advantageous } \\
\text { for the delivery of growth factors and } \\
\text { drugs } \\
\text {-Net cationic charge induces } \\
\text { electrostatic attraction between itself } \\
\text { and the carboxylic acid groups on the } \\
\text { bacterial surface which increases } \\
\text { probability interaction, leading to } \\
\text { antimicrobial activity } \\
\text {-Net cationic charge increases } \\
\text { endothelial permeability, leading to } \\
\text { more effective drug penetration } \\
\text {-Induces superficial thrombosis via } \\
\text { platelet activation leading to } \\
\text { accelerated blood coagulation } \\
\text {-Caps nerve ending, reducing } \\
\text { sensitivity and pain } \\
\text {-Mediates the secretion of } \\
\text { proinflammatory cytokines such as IL- } \\
8 \text { and IL-1 } \beta, \text { which then allow for the } \\
\text { upregulation of M2 macrophages to } \\
\text { promote healing } \\
\text {-Mediation of proinflammatory } \\
\text { cytokines prevents excess } \\
\text { inflammation, thus preventing necrosis } \\
\text { and the escalation of wound pathology } \\
\text {-Induces the release of PDGF- } \alpha, \\
\text { PDGF- } \beta \text { and TGF- } \beta \text { from platelets to } \\
\text { aid in wound regeneration } \\
\text {-Depolymerisation releases N-acetyl- } \\
\beta \text {-d-glucosamine which stimulates } \\
\text { fibroblast proliferation, collagen } \\
\text { remodelling and collagen deposition } \\
\text {-Induces HA release at the site of } \\
\text { injury } \\
\text {-Can be combined and modified with } \\
\text { other polymers }\end{array}$ & $\begin{array}{l}\text {-Drug absorption } \\
\text { decreases at higher } \\
\text { pH } \\
\text {-Poor solubility at } \\
\text { pH } 6+ \\
\text {-Expensive }\end{array}$ & $\begin{array}{l}\text {-Wound } \\
\text { dressing } \\
\text {-Delivery of } \\
\text { growth factors, } \\
\text { antimicrobial } \\
\text { agents and } \\
\text { peptides } \\
\text {-Stem cell } \\
\text { delivery }\end{array}$ & [106-109] \\
\hline $\begin{array}{l}\text { Alginate } \\
\text { (Sourced } \\
\text { from brown } \\
\text { algae) }\end{array}$ & $\begin{array}{l}\text {-Hydrophilic } \\
\text {-Highly } \\
\text { modifiable }\end{array}$ & $\begin{array}{l}\text {-Increase in molecular weight can } \\
\text { enhance the physical properties of the } \\
\text { gel } \\
\text {-Alteration to the molecular weight } \\
\text { distribution can decouple the rate of } \\
\text { degradation from the mechanical } \\
\text { properties } \\
\text {-Different gelation methods: ionic } \\
\text { cross-linking, Covalent cross-linking, } \\
\text { Thermal gelation and cell cross-linking } \\
\text {-Absorbs wound exudate } \\
\text {-Alginate cross-linked with calcium } \\
\text { ions stimulates osteoblast proliferation } \\
\text { and differentiation }\end{array}$ & $\begin{array}{l}\text {-High molecular } \\
\text { weight alginate } \\
\text { solution is hard to } \\
\text { process } \\
\text {-Composition is } \\
\text { affected by the } \\
\text { purity of the } \\
\text { natural source } \\
\text { which can easily } \\
\text { be contaminated } \\
\text { with heavy metals } \\
\text { and proteins } \\
\text {-Covalent cross- } \\
\text { linking is }\end{array}$ & $\begin{array}{l}\text {-Wound } \\
\text { dressing } \\
\text {-Drug delivery } \\
\text { (Small } \\
\text { chemicals) } \\
\text {-Protein } \\
\text { delivery } \\
\text {-Cell culture }\end{array}$ & [110-112] \\
\hline
\end{tabular}


This is a peer-reviewed, accepted author manuscript of the following research article: Man, E., \& Hoskins, C. (Accepted/In press). Towards advanced wound regeneration. European Journal of Pharmaceutical Sciences.

\begin{tabular}{|c|c|c|c|c|c|}
\hline & & $\begin{array}{l}\text {-Antibacterial activity and } \\
\text { biocompatibility can be altered by the } \\
\text { cation used for cross-linking } \\
\text {-Ionic cross-linked gel can heal post- } \\
\text { tensile loading } \\
\text {-high absorption capacity }\end{array}$ & $\begin{array}{l}\text { cytotoxic } \\
\text {-non } \\
\text { biodegradable }\end{array}$ & & \\
\hline $\begin{array}{l}\text { Hyaluronic } \\
\text { acid (HA) }\end{array}$ & $\begin{array}{l}\text {-Biocompatible } \\
\text {-Tuneable } \\
\text {-Innately } \\
\text { bioactive } \\
\text {-Hydrophilic } \\
\text {-Negatively } \\
\text { charged } \\
\text {-Low cytotoxicity } \\
\text {-Anti- } \\
\text { inflammatory }\end{array}$ & $\begin{array}{l}\text {-Biocompatible as the body naturally } \\
\text { secretes HA, resulting in no } \\
\text { immunological reactions } \\
\text {-Can expand by } 1000 \mathrm{x} \text { in volume } \\
\text {-Multifunctional within the ECM, } \\
\text { acting as a osmotic buffer, lubricant } \\
\text { and space buffer. } \\
\text {-Hydrated network mediates the } \\
\text { transport of water and proteins, whilst } \\
\text { restricting pathogen transfer } \\
\text {-Can activate signalling pathways } \\
\text { inducing cell adhesion, differentiation, } \\
\text { proliferation and migration } \\
\text {-Antioxidant effect } \\
\text {-Inhibits macrophage aggregation and } \\
\text { migration thereby preventing } \\
\text { inflammation } \\
\text {-Accelerates the transfer of nutrients } \\
\text { and solutes to the site of injury } \\
\text {-Degraded HA is absorbed by the } \\
\text { wound which stimulates angiogenesis, } \\
\text { cell proliferation and migration } \\
\text {-Stimulates release of TGF- } \beta \\
\text {-Highly abundant in foetal membranes }\end{array}$ & $\begin{array}{l}\text {-Highly expressed } \\
\text { in tumours, is } \\
\text { required in cancer } \\
\text { cell environment, } \\
\text { directs metastasis } \\
\text { (as a result of } \\
\text { TGF- } \beta \\
\text { production) } \\
\text {-HA } \\
\text { concentrations are } \\
\text { higher in areas of } \\
\text { tumour invasion } \\
\text {-Susceptible to } \\
\text { degradation } \\
\text {-sub-optimal } \\
\text { mechanical } \\
\text { properties }\end{array}$ & $\begin{array}{l}\text {-Drug delivery } \\
\text {-Scaffold }\end{array}$ & [113-115] \\
\hline
\end{tabular}


This is a peer-reviewed, accepted author manuscript of the following research article: Man, E., \& Hoskins, C. (Accepted/In press). Towards advanced wound regeneration. European Journal of Pharmaceutical Sciences.

\begin{tabular}{|c|c|c|c|c|c|}
\hline & & $\begin{array}{l}\text {-Plays a key role in each phase of } \\
\text { wound healing } \\
\text {-Collagen fibres direct cellular } \\
\text { migration } \\
\text {-Inhibition of Matrix } \\
\text { metalloproteinases (MMPs), which } \\
\text { contribute to chronic wound } \\
\text { development when in excess } \\
\text {-Cellular functions are regulated by the } \\
\text { ECM which is primarily consists of } \\
\text { collagen } \\
\text {-Keratinocytes recognises and } \\
\text { migrates onto collage I layers }\end{array}$ & & & \\
\hline Cellulose & $\begin{array}{l}\text {-Water insoluble } \\
\text {-Biodegradable } \\
\text {-Low density } \\
\text {-Biocompatible } \\
\text {-Good } \\
\text { bioavailability } \\
\text {-Adequate } \\
\text { durability } \\
\text {-Mechanically } \\
\text { stable } \\
\text {-Inexpensive } \\
\text {-Environmentally } \\
\text { friendly } \\
\text {-Non-toxic } \\
\text {-Non-allergenic } \\
\text {-Haemostatic } \\
\text {-Inherently } \\
\text { hydrophobic }\end{array}$ & $\begin{array}{l}\text {-Due to the abundance of hydroxyl } \\
\text { groups within cellulose, it can be used } \\
\text { to create polymers gels with various } \\
\text { properties and structures } \\
\text {-Highly abundant, is found within } \\
\text { plants in its pure form } \\
\text {-Native cellulose hydrogels formed via } \\
\text { physical cross-linking } \\
\text {-High abundance of hydroxyl groups } \\
\text { allow for a large variety of surface } \\
\text { modifications } \\
\text {-Can physically prevent the deposition } \\
\text { of pathogens onto the wound area } \\
\text {-Can be doped with nanometals to } \\
\text { promote antibacterial effects } \\
\text { Cotton cellulose: } \\
\text {-Highly crystalline and fibrillar } \\
\text {-Hydrophilic } \\
\text {-High surface energy } \\
\text {-Thermally stable }\end{array}$ & $\begin{array}{l}\text {-Poor solubility in } \\
\text { commonly used } \\
\text { solvents } \\
\text {-Poor dimensional } \\
\text { stability } \\
\text { - As a wound } \\
\text { dressing cellulose } \\
\text { has a reduced } \\
\text { water absorption } \\
\text { capacity and can } \\
\text { adhere to the } \\
\text { wound site } \\
\text {-No inherent } \\
\text { antibacterial } \\
\text { properties }\end{array}$ & $\begin{array}{l}\text {-Drug delivery } \\
\text {-Wound } \\
\text { dressing }\end{array}$ & [119-121] \\
\hline
\end{tabular}

